\title{
High Functionalization of Magnesium Alloy Surface by Superhydrophobic Treatment
}

\author{
Takahiro Ishizaki ${ }^{1}$, SunHyung Lee ${ }^{2}$ and Katsuya Teshima ${ }^{2}$ \\ ${ }^{1}$ National Institute of Advanced Industrial Science and \\ Technology (AIST), Nagoya 463-8560 \\ ${ }^{2}$ Department of Environmental Science and Technology, \\ Faculty of Engineering, Shinshu University, Nagano 380-8553
}

Japan

\section{Introduction}

Magnesium and its alloys have excellent physical and mechanical properties such as low density, good electromagnetic shielding, and high strength/weight ratio (Gray \& Luan, 2002; Yong et al., 2008). Thus, they are expected to be applied to various industries such as the aerospace, automobile, and railway industries (Mordike \& Ebert, 2001; Phani et al., 2006; Ha \& Kim, 2006). Their poor corrosion resistance, however, hinders their use on a larger scale. The corrosion of magnesium and magnesium alloys occurs via the following reaction (Baril et al., 2007; Song el al., 1997):

$$
\begin{gathered}
2 \mathrm{Mg} \rightarrow 2 \mathrm{Mg}^{+}+2 \mathrm{e}^{-} \\
2 \mathrm{Mg}^{+}+2 \mathrm{H}_{2} \mathrm{O} \rightarrow 2 \mathrm{Mg}^{2+}+2 \mathrm{OH}^{-}+\mathrm{H}_{2} \\
2 \mathrm{H}_{2} \mathrm{O}+2 \mathrm{e}^{-} \rightarrow \mathrm{H}_{2}+2 \mathrm{OH}^{-} \\
2 \mathrm{Mg}^{2+}+4 \mathrm{OH}^{-} \rightarrow 2 \mathrm{Mg}(\mathrm{OH})_{2}
\end{gathered}
$$

According to equations (1), (2), (3) and (4), the contact of magnesium alloy with water triggers the corrosion reaction. Thus, it is important to prevent the contact of magnesium alloy with water to suppress the progress of corrosion. In order to realize this, various methods such as chemical conversion, electroplating, and anodic oxidization have been developed (Barchiche et al., 2007; Lian et al., 2006; Liu \& Gao, 2006; Montemor \& Ferreira, (2007). The films prepared by these surface treatments always contain pores, pine-holes, cracks etc. The porosity and defect density are critically important to the quality of a film. In addition, the film thickness and film density are important factors from the viewpoint of anticorrosion performance. However, the advantage offered by the lightweight properties of magnesium alloy might be lost if the thickness and density of the applied coating are increased. Thus, it is crucial to develop a coating technology to improve anticorrosion performance, while maintaining the advantage offered by the lightweight properties of magnesium alloys. A corrosion resistant hydrophobic film formed on AZ91D Mg alloy through a simple dipping process has recently been reported (Song, 2010). This hydrophobic 
film improved the corrosion resistance of magnesium alloy AZ91. Thus, a superhydrophobic coating would be also a promising technology for improving anticorrosion performance because it would inhibit the contact of a surface with water and environmental humidity. A superhydrophobic surface would be of great importance to many industrial applications and could present a solution to the long-standing problems of environmental contamination and corrosion of metals and metal alloys (Liu et al., 2009; Roach et al., 2008; Xu et al., 2008).

The superhydrophobic phenomenon can be commonly observed in many plants in nature such as lotus leaf and it is known as the Lotus effect (Barthlott \& Neinhuis, 1997). The superhydrophobic surfaces on many plants are created by a cooperation of binary structures at nano- and micrometers scales and coverage of wax-like materials on them. The special micro-nano-binary structures increase the surface roughness and minimize the contact area between the leaf and liquid, which can endow the leaf with self-cleaning superhydrophobicity. The development of various fabrication techniques for superhydrophobic surface by mimicking the surface of the lotus leaves has been a hot subject. The artificial superhydrophobic surfaces have been fabricated mostly by controlling the surface roughness and topography, followed by surface modification using organic monolayers with hydrophobic functional groups (Guo et al., 2005; Qian \& Shen, 2005). The controls of the surface roughness and topography have been accomplished through various techniques such as anodic oxidation (Thieme et al., 2001), electrodeposition and chemical etching (Shi et al., 2005; Shirtcliffe et al., 2005; Zhang et al., 2004), plasma etching (Lejeune et al., 2006), laser treating (Khorasani et al., 2005), chemical vapour deposition (Huang et al., 2005), sol-gel processing (Shirtcliffe et al., 2003), electrospinning (Acatay et al., 2004; Singh et al., 2005), and so on.

Recently, superhydrophobic treatments have been applied to various engineering material surfaces such as steel, copper, zinc, and aluminum, to improve their corrosion performances (He et al., 2009; Qian \& Shen, 2005; Qu et al., 2007; Thieme \& Worch, 2006; Wang et al., 2006). Liu et al. demonstrated the preparation of a superhydrophobic surface on copper by chemical etching and surface modification with n-tetradecanoic acid and investigated the corrosion resistant performance in seawater by electrochemical measurements (Liu et al., 2007). They concluded that the superhydrophobic surface considerably reduced the corrosion rate of copper due to its special morphology. He et al. fabricated a superhydrophobic surface on anodized aluminum by modifying myristic acid and estimated the corrosion resistant performance by electrochemical impedance spectroscopy (He et al., 2009). The superhydrophobic surface greatly improved the corrosion resistance of aluminum. In this way, a superhydrophobic surface has been shown to be effective for improving the corrosion resistance of engineering materials. However, it was widely assumed that the advantages of a superhydrophobic surface would disappear if it was completely immersed in a solution; thus, there was little attention paid to the application of superhydrophobic surfaces equipped with anticorrosion performances to metal surfaces. As a consequence, there are few reports on the application of a superhydrophobic surface to magnesium alloys. Jiang et al. reported the fabrication of a bioinspired superhydrophobic surface on Mg-Li alloy (Liu et al., 2008). The superhydrophobic surface was fabricated by chemical etching and surface modification with a $\mathrm{CF}_{3}$-terminated self-assembled monolayer (fluoroalkyl silane self-assembled monolayer: FAS-SAM). They estimated the corrosion resistant performance by investigating the relationship between the time of exposure to air 
and the change in static water contact angles on the superhydrophobic surface of the Mg-Li alloy. The surface showed stably superhydrophobic properties for over three months. However, the surface was not exposed to a corrosive environment such as diluted $\mathrm{NaCl}$ aqueous solution, so it is difficult to conclude that the superhydrophobic property provides high corrosion resistance to the magnesium alloy.

In this chapter, we introduce some experimental results on the fabrication and corrosion resistant performance of superhydrophobic surface formed on magnesium alloy. At first, we present an example of the formation of nanosheets on magnesium alloy surface. The crystalline nanosheets were successfully formed on magnesium alloy AZ31 by a facile surfactant-free hydrothermal treatment using aqueous solution. The nanosheets formed surface had hierarchical structures at micro- and nanometer scales so they could be used as a template of superhydrophobic surface. Next, we show superhydrophobic surface on magnesium alloy fabricated by microwave plasma-enhanced chemical vapor deposition (MPECVD) process. Here, the anticorrosion resistance and the chemical stability of the superhydrophobic film were described based on the results of electrochemical impedance spectroscopy (EIS) and water contact angle measurements. Finally, we describe a facile, simple, and time-saving method to create superhydrophobic surface on magnesium alloy by a simple immersion process at room temperature. The superhydrophobic surface was fabricated through the following two steps. First, crystalline $\mathrm{CeO}_{2}$ film was vertically formed on the magnesium alloy by immersion in cerium nitrate aqueous solution within 20 min. Next, the film were covered with fluoroalkylsilane molecules (FAS) within 30 min by immersing in toluene solution containing FAS and tetrakis(trimethylsiloxy)titanium (TTST). The FAS coated $\mathrm{CeO}_{2}$ film showed a static contact angle of more than $150^{\circ}$, that is, superhydrophobic property. The chemical stability of the superhydrophobic surface on magnesium alloy AZ31 would be also discussed.

\section{Formation of nanosheets on magnesium alloy surface}

In this section, we report a facile surfactant-free synthesis of vertically self-aligned $\mathrm{Mg}_{1-}$ ${ }_{x} \mathrm{Al}_{\mathbf{x}}(\mathrm{OH})_{2}\left(\mathrm{NO}_{3}\right)_{\times} \cdot n \mathrm{H}_{2} \mathrm{O}, \quad \mathrm{Mg}_{1-\mathrm{x}} \mathrm{Al}_{\mathbf{x}}(\mathrm{OH})_{2}\left(\mathrm{NO}_{3}\right)_{\times} \cdot n \mathrm{H}_{2} \mathrm{O}$ and $\mathrm{Mg}(\mathrm{OH})_{2}$, and $\mathrm{Mg}(\mathrm{OH})_{2}$ nanosheets on a magnesium alloy substrate (AZ31); these nanosheets were fabricated on magnesium alloy AZ31 as a hierarchical structure at micro- and nanometer scales by a simple hydrothermal synthesis using aqueous solutions. The hierarchical structures could be used as a template of superhydrophobic surface.

Aqueous ammonium solution containing $\mathrm{NH}_{4} \mathrm{NO}_{3}$ and $\mathrm{NaOH}$ was used for the fabrication of $\mathrm{Mg}(\mathrm{OH})_{2}$ nanosheets. This ammonium solution was obtained by dissolving $0.1 \mathrm{M}$ $\mathrm{NH}_{4} \mathrm{NO}_{3}$ and then adding $1 \mathrm{ml}$ of $0.1 \mathrm{M} \mathrm{NaOH}$. The dissolution process was carried out at room temperature by stirring the solution mixture for a few minutes. All chemicals were of regent grade and used without any pretreatment. Magnesium alloy AZ31 (composition: $2.98 \% \mathrm{Al}, 0.88 \% \mathrm{Zn}, 0.38 \% \mathrm{Mn}, 0.0135 \% \mathrm{Si}, 0.001 \% \mathrm{Cu}, 0.002 \% \mathrm{Ni}, 0.0027 \% \mathrm{Fe}$, and the rest is $\mathrm{Mg}$ ) with a thickness of $1.5 \mathrm{~mm}$ was used as the substrate. The substrates were ultrasonically cleaned in ethanol for $10 \mathrm{~min}$. After the cleaning, the substrates were dried with inert Ar gas. The cleaned magnesium alloy substrates were introduced in a Teflon-lined autoclave with a $50 \mathrm{ml}$ capacity. The autoclave was filled with the aqueous ammonium solution mixture to fill $40 \%$ of its capacity. The autoclave was maintained at temperatures of $120-180{ }^{\circ} \mathrm{C}$ for $1-24$ $\mathrm{h}$ and subsequently left to cool to room temperature. After the samples were subjected to the treatments, the substrate was ultrasonically cleaned in ethanol for $10 \mathrm{~min}$ and dried with Ar gas. 
Figures 1(a), 1(b), 1(c), and 1(d) show FE-SEM images of the sample surfaces after hydrothermal treatment at $150{ }^{\circ} \mathrm{C}$ for $1,3,6$, and $12 \mathrm{~h}$, respectively. All the samples exhibit nanosheets that are aligned at fairly inclined angles with respect to the surface. When the treatment time was less than $3 \mathrm{~h}$, the nanosheets were locally formed on the surfaces. In contrast, after treatment for over $12 \mathrm{~h}$, the nanosheets were observed to be vertically aligned over the entire substrate surface and appeared to be partly in the form of multi-layers (Figures 1(c) and (d)). Figures 1(e)-(h) show the enlarged versions of the FE-SEM images shown in Figures 1(a)-(d), respectively. The vertically aligned nanosheets became dense as the treatment time increased. The nanosheets exhibit an edge length in the range of approximately $50-750 \mathrm{~nm}$ and a thickness of $20-50 \mathrm{~nm}$. It was difficult to determine the height of the fabricated nanosheets because of the flake-like morphology of the crystallites; moreover, several individual crystals were found to have a length of approximately $1 \mu \mathrm{m}$.

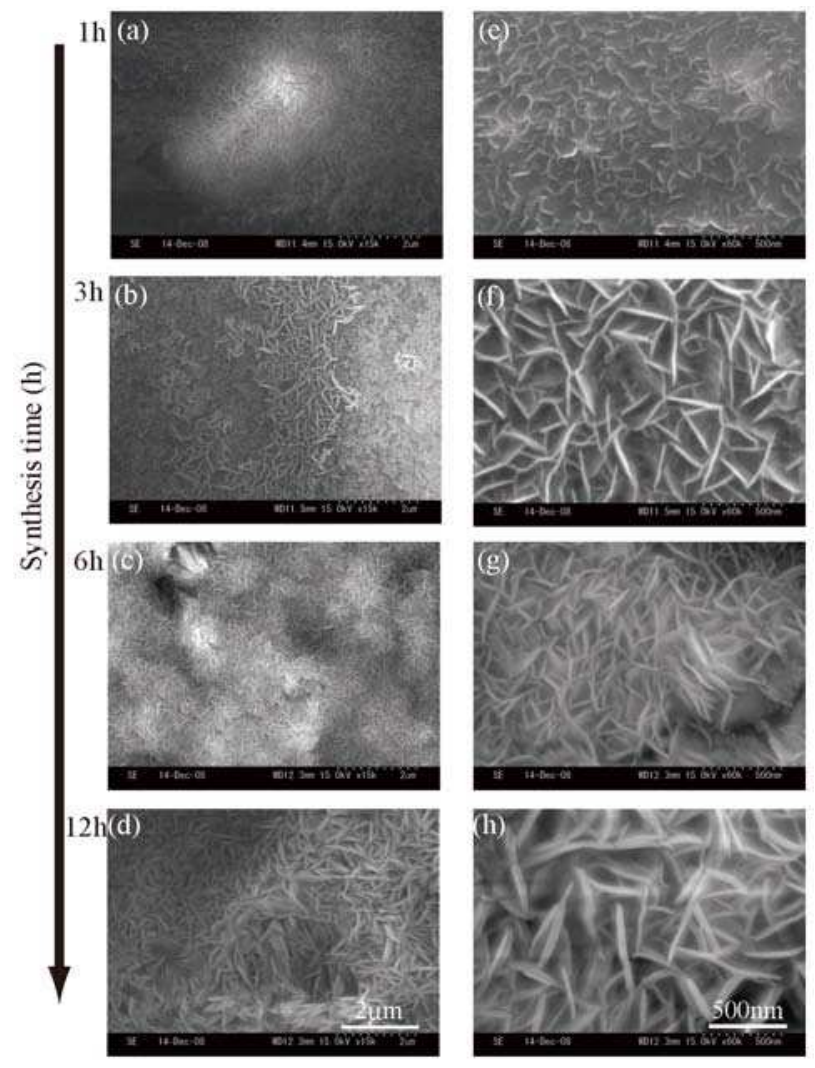

Fig. 1. FE-SEM images of sample surfaces after hydrothermal treatment at $150{ }^{\circ} \mathrm{C}$ for (a) $1 \mathrm{~h}$, (b) $3 \mathrm{~h}$, (c) $6 \mathrm{~h}$, and (d) $12 \mathrm{~h}$. (e), (f), (g), and (h) are the enlarged FE-SEM images of (a), (b), (c), and (d), respectively. [Reproduced by permission of The Royal Society of Chemistry, CrystEngComm., 2009, 11, 2338.]

Figures 2(a), 2(b), and 2(c) show FE-SEM images of the samples surfaces hydrothermally treated for $6 \mathrm{~h}$ at 120,150 , and $180^{\circ} \mathrm{C}$, respectively. These images show that the sheets are 
predominantly perpendicular to the substrate. At the treatment temperature of $120{ }^{\circ} \mathrm{C}$, we clearly observe a rosette-like structure formed by the curved nanosheets. The nanosheets with sizes of $0.5-1 \mu \mathrm{m}$ are densely formed in the rosette-like structure. The rosette-like structures somewhat appear to be laid on a carpet of vertically aligned nanosheets. An increase in the treatment temperature to $150{ }^{\circ} \mathrm{C}$ was found to result in the formation of compact and continuous nanosheets due to an increase in nucleation and growth rates. When the treatment temperature reaches $180{ }^{\circ} \mathrm{C}$, dense hexagonal nanosheets were observed. The edges of these hexagonal formations are clearly observed. This indicates that the crystalline quality of these nanosheets is very high. The size and thickness of the nanosheets obtained at $180^{\circ} \mathrm{C}$ are larger than those of the nanosheets treated at $150{ }^{\circ} \mathrm{C}$.

(a)

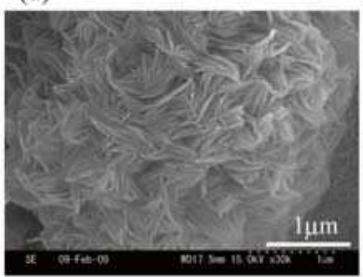

$120^{\circ} \mathrm{C}$ (b)

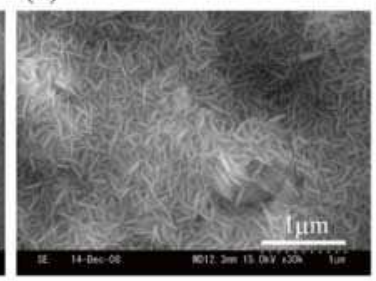

$150^{\circ} \mathrm{C}$ (c)

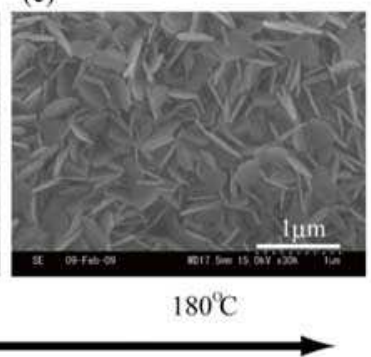

Temperature $\left({ }^{\circ} \mathrm{C}\right)$

Fig. 2. FE-SEM images of sample surfaces after hydrothermal treatment for $6 \mathrm{~h}$ at (a) $120^{\circ} \mathrm{C}$, (b) $150{ }^{\circ} \mathrm{C}$, and (c) $180^{\circ} \mathrm{C}$. [Reproduced by permission of The Royal Society of Chemistry, CrystEngComm., 2009, 11, 2338.]

Figure 3 shows the XRD patterns of the obtained samples after their hydrothermal treatment at $150{ }^{\circ} \mathrm{C}$ for $3-24 \mathrm{~h}$. In the case of all samples, some peaks attributable to the hydrotalcite (HT)-like structure were clearly observed, which were assigned to $\mathrm{Mg}_{1-}$ ${ }_{x} \mathrm{Al}_{x}(\mathrm{OH})_{2}\left(\mathrm{NO}_{3}\right)_{x} \cdot n \mathrm{H}_{2} \mathrm{O}$ intercalated with nitrate anions $(\mathrm{Xu} \& \mathrm{Zeng}, 2001)$. The diffraction peaks are indexed according to the $3 R$ symmetry (Cavani et al., 1991; Kuma et al., 1989; Rives \& Ulibarri, 1999). The intensity of the diffraction peak corresponding to the [003] plane is almost the same, irrespective of the treatment time. This indicates that the crystal growth of the $\mathrm{Mg}_{1-x} \mathrm{Al}_{\mathrm{x}}(\mathrm{OH})_{2}\left(\mathrm{NO}_{3}\right)_{\mathrm{x}} \cdot n \mathrm{H}_{2} \mathrm{O}$ in the [003] plane occurs within $3 \mathrm{~h}$ of initiating the hydrothermal treatment at $150{ }^{\circ} \mathrm{C}$. The XRD pattern of the vertically aligned nanosheets on the AZ31 substrate is distinctly different from that of the randomly oriented HT microcrystalline powder due to the observation of several rational orders of $(00 l)$ reflections (Yates \& West, 1983). Such an arrangement of the hexagonal nanosheets with the c-axis parallel to and the ab-face perpendicular to the geometrically untreated substrate has not been observed in HT films thus far. Chen et al. have reported that the hexagonal nanosheets with $c$-axis parallel to the porous anodic alumina/aluminium (POA) substrate, which was fabricated by anodizing an aluminium metal sheet, were formed on the POA substrate (Chen et al., 2006). This might be due to the change in the surface energy with changing surface roughness because of the porous nature of the substrate surface. In addition to the peaks attributable to $\mathrm{Mg}_{1-x} \mathrm{Al}_{x}(\mathrm{OH})_{2}\left(\mathrm{NO}_{3}\right)_{x} \cdot n \mathrm{H}_{2} \mathrm{O}$, a few peaks attributable to hexagonal $\mathrm{Mg}(\mathrm{OH})_{2}$ are also clearly observed. A diffraction peak of [101] reflection, which has the highest intensity according to the JCPDS file number 44-1482, become stronger with 


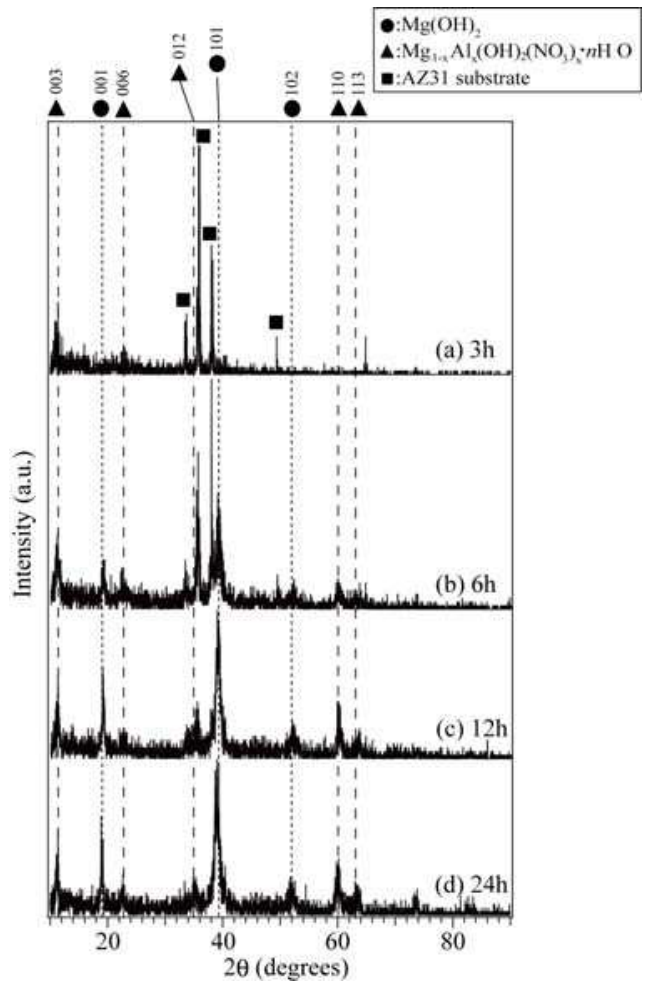

Fig. 3. XRD patterns of sample surfaces after hydrothermal treatment at $150{ }^{\circ} \mathrm{C}$ for (a) $3 \mathrm{~h}$, (b) $6 \mathrm{~h}$, (c) $12 \mathrm{~h}$, and (d) $24 \mathrm{~h}$. [Reproduced by permission of The Royal Society of Chemistry, CrystEngComm., 20019, 11, 2338.]

increasing treatment time; this observation implies the formation of hexagonal $\mathrm{Mg}(\mathrm{OH})_{2}$. It should be noted that the intensity of the diffraction peak of [001] plane increased with increasing treatment time. According to JCPDS file number 44-1482, the intensity ratio of $I_{001} / I_{101}$ is 0.53 . However, the intensity ratio of $I_{001} / I_{101}$ for the fabricated $\operatorname{Mg}(\mathrm{OH})_{2}$ nanosheets increased from 0.44 to 0.63 with treatment time. This indicates that the $\mathrm{Mg}(\mathrm{OH})_{2}$ crystallite dimensions are preferentially restricted along the crystallographic $c$-axis. This result is in good agreement with the SEM observations. Figures 4(a), 4(b), and 4(c) show the XRD patterns of the samples after hydrothermal treatment for $6 \mathrm{~h}$ at 120,150, and $180{ }^{\circ} \mathrm{C}$, respectively. At the treatment temperature of $120^{\circ} \mathrm{C}$, two peaks originating from the HT-like structure and assignable to $\mathrm{Mg}_{1-x} \mathrm{Al}_{x}(\mathrm{OH})_{2}\left(\mathrm{NO}_{3}\right)_{\times} \cdot n \mathrm{H}_{2} \mathrm{O}$ are clearly observed. The two peaks at $2 \theta=10.4^{\circ}$ and $20.8^{\circ}$ are assigned to the [003] and [006] reflections of $\mathrm{Mg}_{1-}$ ${ }_{x} \mathrm{Al}_{\mathrm{x}}(\mathrm{OH})_{2}\left(\mathrm{NO}_{3}\right)_{\times} \cdot n \mathrm{H}_{2} \mathrm{O}$, respectively. This means that the treated surfaces were well crystallized with a preferential hexagonal orientation along the [003] plane, which is a characteristic feature of the spontaneous texture axis of $\operatorname{Mg}_{1-x} \mathrm{Al}_{x}(\mathrm{OH})_{2}\left(\mathrm{NO}_{3}\right)_{\times} \cdot n \mathrm{H}_{2} \mathrm{O}$. Crystalline $\mathrm{Mg}(\mathrm{OH})_{2}$ phases were not formed at the treatment temperature of $120{ }^{\circ} \mathrm{C}$. This indicates that the rosette-like structure formed by the curved nanosheets and the vertically aligned nanosheets beneath the rosette-like structure are crystalline $\mathrm{Mg}_{1-}$ ${ }_{x} \mathrm{Al}_{x}(\mathrm{OH})_{2}\left(\mathrm{NO}_{3}\right)_{x} \cdot n \mathrm{H}_{2} \mathrm{O}$. The XRD pattern in Figure $4(\mathrm{~b})$ shows some peaks that are 


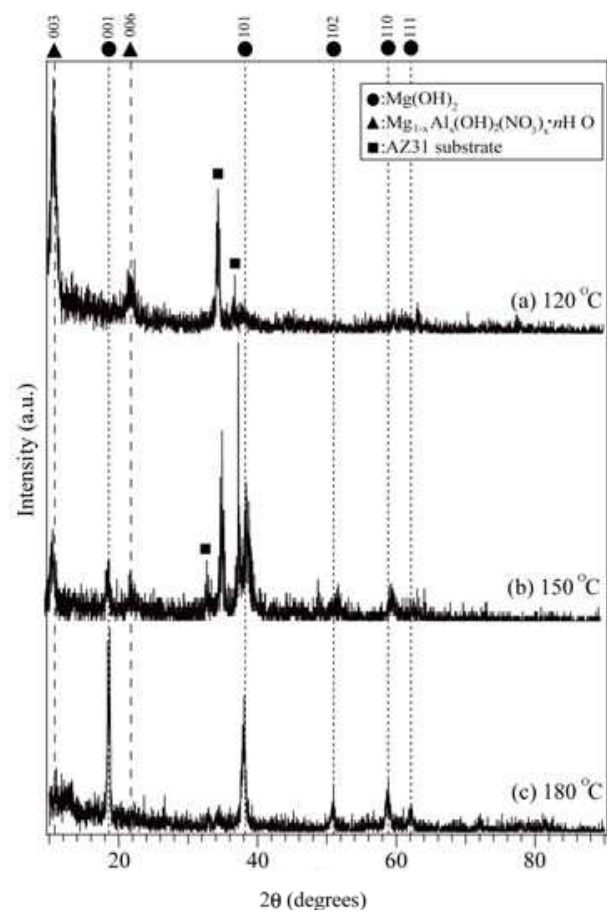

Fig. 4. XRD patterns of sample surfaces after hydrothermal treated for $6 \mathrm{~h}$ at (a) $120^{\circ} \mathrm{C}$, (b) $150{ }^{\circ} \mathrm{C}$, and (c) $180^{\circ} \mathrm{C}$. [Reproduced by permission of The Royal Society of Chemistry, CrystEngComm., 2009, 11, 2338.]

attributable to crystalline hexagonal $\mathrm{Mg}_{1-\mathrm{x}} \mathrm{Al}_{\mathrm{x}}(\mathrm{OH})_{2}\left(\mathrm{NO}_{3}\right)_{\times} \cdot n \mathrm{H}_{2} \mathrm{O}$ and $\mathrm{Mg}(\mathrm{OH})_{2}$. An increase in the treatment temperature led to the formation of crystalline $\mathrm{Mg}(\mathrm{OH})_{2}$. The XRD pattern of the sample surface treated at $180{ }^{\circ} \mathrm{C}$ shows only some peaks assignable to $\mathrm{Mg}(\mathrm{OH})_{2}$. The degree of orientation was roughly estimated from the ratio of the peak intensities arising from [001] and [101] planes, i.e., $I_{001} / I_{101}$, which is 0.53 for the powder diffraction standard of $\mathrm{Mg}(\mathrm{OH})_{2}$. The degree of orientation was estimated to be 1.49 for the sample treated at 180 ${ }^{\circ} \mathrm{C}$, indicating the high degree of crystallographic orientation in this sample. This result is in agreement with the SEM observations. At this temperature, the crystallites exhibited a clear plate-like shape with the edges preferentially directed out of the AZ31 substrate. This indicates that the strong preference of crystallographic orientation observed can be regarded as an increase in the growth rate of the crystallites due to an increase in the treatment temperature.

Figure 5 shows the FT-IR spectra of the powder samples hydrothermally treated at $150{ }^{\circ} \mathrm{C}$ in the region of $400-4000 \mathrm{~cm}^{-1}$. The most predominant spectral feature is the intense sharp peak observed at $3696.9 \mathrm{~cm}^{-1}$. It has been known that pure $\mathrm{Mg}(\mathrm{OH})_{2}$ exhibits a single band at $3698 \mathrm{~cm}^{-1}$, owing to the high basicity of its O-H groups (Bensi, 1959; Xu \& Zeng, 2000). Another sharp peak at around $1384.6 \mathrm{~cm}^{-1}$ is attributable to the $v_{3}$ vibrational mode of $\mathrm{NO}_{3}{ }^{-}$ in the interlayer with $D_{3 \mathrm{~h}}$ symmetry (Yates \& West, 1983). A weak shoulder band at around $830 \mathrm{~cm}^{-1}$ appears due to the $v_{2}$ vibrational mode of the same anion (Chisem \& Jones, 1994; Qian \& Zeng, 1997; Xu \& Zeng, 1999). A weak broad band in the region of $1630-1650 \mathrm{~cm}^{-1}$ is 
attributed to the hydroxyl-deformation mode of water (Kloprogge et al., 2005). The lattice vibrations of metal-oxygen bonds (M-O) are also observed at around $550 \mathrm{~cm}^{-1}$ (Kannan et al., 1995; Labajos et al., 1992). It is possible that some of these bands overlap with the broad band due to the d-mode of $\mathrm{O}-\mathrm{H}$ or that the vibrations occur in the wavenumber region below the measured range. The XPS spectra of the sample treated at $150{ }^{\circ} \mathrm{C}$ revealed that the $\mathrm{Mg}$ 1s peak arising from the formed nanosheets can be separated into two peaks. The two peaks centred at 1302.7 and $1303.8 \mathrm{eV}$ are assigned to $\mathrm{Mg}(\mathrm{OH})_{2}$ and metal $\mathrm{Mg}$, respectively (Haycock et al., 1978; Yates \& West, 1983). Trace amount of aluminium with a concentration of less than 5 at $\%$ was detected in the nanosheets at the vicinity of the surface. This supports the fact that the nanosheets comprised of $\mathrm{Mg}_{1-x} \mathrm{Al}_{x}(\mathrm{OH})_{2}\left(\mathrm{NO}_{3}\right)_{x} \cdot n \mathrm{H}_{2} \mathrm{O}$ and $\mathrm{Mg}(\mathrm{OH})_{2}$.

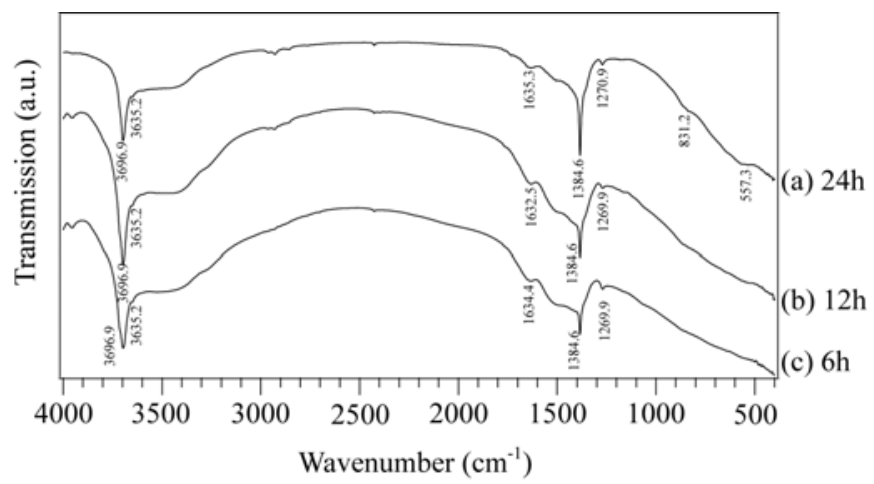

Fig. 5. FT-IR spectra of sample surfaces after hydrothermal treatment at $150{ }^{\circ} \mathrm{C}$ for (a) $6 \mathrm{~h}$, (b) $12 \mathrm{~h}$, and (c) $24 \mathrm{~h}$. [Reproduced by permission of The Royal Society of Chemistry, CrystEngComm., 2009, 11, 2338.]

Figure 6 shows the representative TEM images of the powder sample for the nanosheets formed on the magnesium alloy substrate that was hydrothermally treated at $150{ }^{\circ} \mathrm{C}$ for 24 h. Two main morphologies are observed: the vertically and horizontally aligned nanosheets and the nanoneedles. In Figures 6(b) and 6(c), several vertically aligned nanosheets with a thickness of 10-30 nm and nanoneedles with diameters of ca. 3-10 nm can be observed. The selected area electron diffraction (SAED) patterns exhibit rings corresponding to the [001], [101], and [102] planes of $\mathrm{Mg}(\mathrm{OH})_{2}$. These patterns are consistent with the XRD patterns. In the higher magnification TEM image shown in Figures 6(b) and 6(c), the horizontally aligned nanosheets were also observed; these nanosheets were thin with large areas. Figure 6(d) shows the high-resolution TEM (HRTEM) image of the nanosheet. Three types of lattice fringes $\left(L_{a}, L_{b}\right.$, and $\left.L_{c}\right)$ originating from the single domain are clearly observed. All the lattice-fringe spacings are found to be equal to those of the 101 plane of hexagonal $\mathrm{Mg}(\mathrm{OH})_{2}$. The prominence of the lattice fringe of $d_{101}$ among the observed nanocrystallites suggests that the aggregative growth of the nanosheets is concentrated in the [101] direction. In addition,two types of Moire fringes $\left(R_{1}\right.$ and $\left.R_{2}\right)$ are clearly observed in the HRTEM image. The Moire fringes are attributed to the rotation of the lattice planes having equal lattice spacing. According to previous studies, the nanoneedles could be the vertically aligned nanosheets or the nanosheets that are rolled up (Chen \& Gao, 2004; Chen \& Gao, 2005). The nanosheets would aggregate vertically by driving forces arising from the local stress and the decrease in the surface-free energy of the nanosheets. It is believed that the thin nanosheets 
(a)

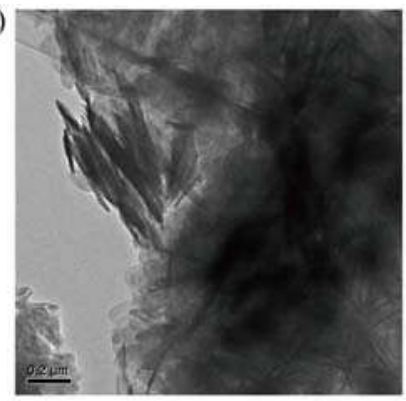

(c)

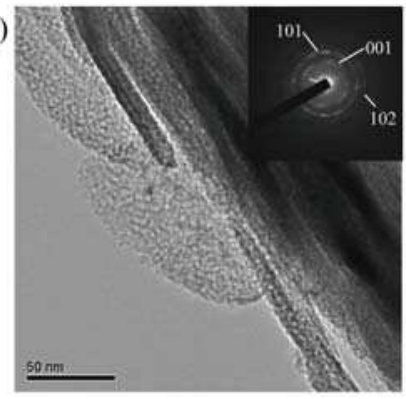

(b)

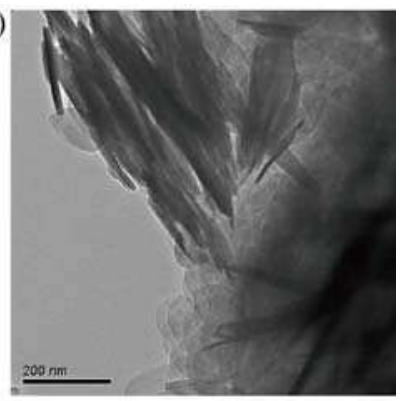

(d)

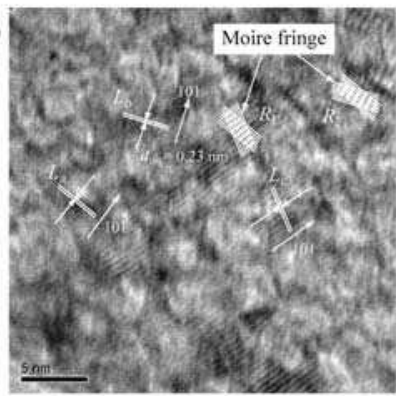

Fig. 6. (a) TEM image of powder sample of nanosheets hydrothermally treated at $150{ }^{\circ} \mathrm{C}$ for $24 \mathrm{~h}$; (b) enlarged TEM image of (a); and (c) enlarged TEM image of (b). The inset shows the ED pattern of the nanosheet; (d) shows the HRTEM image of the nanosheet. [Reproduced by permission of The Royal Society of Chemistry, CrystEngComm., 2009, 11, 2338.]

specific surface energy, Liete et al. suggested that the surface energy of the 001 facet of hexagonal $\mathrm{SiO}_{2}$, which is comparable to the hexagonal $\mathrm{Mg}(\mathrm{OH})_{2}$, is higher than that of the other facets (Leite et al., 2003). In our system, the ammonium ion may preferentially get adsorbed on the 001 surface of hexagonal $\mathrm{Mg}(\mathrm{OH})_{2}$ to lower the high potential energy of the system. This might hinder the growth of nanocrystals in the [001] direction.

The growth behaviours of the nanosheets, comprising of crystalline $\mathrm{Mg}_{1}$ ${ }_{x} \mathrm{Al}_{\times}(\mathrm{OH})_{2}\left(\mathrm{NO}_{3}\right)_{\times} \cdot n \mathrm{H}_{2} \mathrm{O}, \mathrm{Mg}_{1-\mathrm{x}} \mathrm{Al}_{\times}(\mathrm{OH})_{2}\left(\mathrm{NO}_{3}\right)_{\times} \cdot n \mathrm{H}_{2} \mathrm{O}$ and $\mathrm{Mg}(\mathrm{OH})_{2}$, and $\mathrm{Mg}(\mathrm{OH})_{2}$, depend on the experimental conditions; the single most important factor influencing the growth behaviour was found to be the treatment temperature. At $120^{\circ} \mathrm{C}$, the rosette-like structure formed by the curved nanosheets of crystalline $\mathrm{Mg}_{1-x} \mathrm{Al}_{x}(\mathrm{OH})_{2}\left(\mathrm{NO}_{3}\right)_{x} \cdot n \mathrm{H}_{2} \mathrm{O}$ was observed. It is worth noting that some previously reported $\mathrm{LDH}$ intercalated compounds showed a curved plate-like or sheet morphology (Ogawa \& Asai, 2000; Xu \& Braterman, 2003); these morphologies are formed by the cooperative organization of the intercalated anions and the cationic metal hydroxide layers. In our study, the unique morphology observed is considered to be induced by the interaction extrusion stress between nanocrystals. On increasing the treatment temperature to $150{ }^{\circ} \mathrm{C}$, the shapes of the nanosheets are changed. The sample contains two types of crystalline structures, $\mathrm{Mg}_{1-\mathrm{x}} \mathrm{Al}_{\mathbf{x}}(\mathrm{OH})_{2}\left(\mathrm{NO}_{3}\right)_{\times} \cdot n \mathrm{H}_{2} \mathrm{O}$ and $\mathrm{Mg}(\mathrm{OH})_{2}$; thus, no traces of curved nanosheets are observed in the sample treated at $150{ }^{\circ} \mathrm{C}$. This might be due to the fact that on formation of $\mathrm{Mg}(\mathrm{OH})_{2}$, the interaction extrusion stress between the nanocrystals was relaxed. As a result, the interaction extrusion stress during the cooperative organization of the intercalated anions and the cationic metal hydroxide layers 
could produce the curved structures. As shown in Figure 2(c), further increase in treatment temperature to $180{ }^{\circ} \mathrm{C}$ yielded larger crystals with sharp edges. The crystal structure in the crystallites corresponded to $\mathrm{Mg}(\mathrm{OH})_{2}$. At this temperature, the crystallites exhibited a distinct plate-like shape with the edges preferentially directed out of the AZ31 substrate. It is likely that this layer grows via a dissolution-precipitation mechanism. Nordlien et al. have supposed that amorphous platelets of $\mathrm{Mg}(\mathrm{OH})_{2}$ were initially formed by the precipitation of $\mathrm{Mg}^{2+}$ or other soluble magnesium species (Nordlien et al., 1997). These nanosheets appeared to be formed by the mechanical rupture of the outer layer of the amorphous $\mathrm{Mg}(\mathrm{OH})_{2}$ film rather than the precipitation of soluble magnesium hydroxide; this is because the nanosheets were locally formed on the surface, as shown in Figure 1(a). The film rupture can be attributed to the internal stress generated in the formed amorphous $\mathrm{Mg}(\mathrm{OH})_{2}$ film (Schultze \& Lohrengel, 2000). With an increase in treatment time, the crystalline $\mathrm{Mg}(\mathrm{OH})_{2}$ nanosheeets could be formed by the precipitation of magnesium hydroxide and the subsequent formation of the amorphous $\mathrm{Mg}(\mathrm{OH})_{2}$ film.

Crystalline nanosheets were successfully formed on magnesium alloy AZ31 by carrying out a facile surfactant-free hydrothermal treatment. The crystal structures and shapes of the nanosheets changed with the treatment temperature. We found that on treatment at $120^{\circ} \mathrm{C}$, rosette-like structure made from curved nanosheets of crystalline $\mathrm{Mg}_{1-}$ ${ }_{x} \mathrm{Al}_{x}(\mathrm{OH})_{2}\left(\mathrm{NO}_{3}\right)_{x} \cdot n \mathrm{H}_{2} \mathrm{O}$ was formed. An increase in treatment temperature to $150{ }^{\circ} \mathrm{C}$ led to the formation of plate-like nanosheets of crystalline $\mathrm{Mg}_{1-x} \mathrm{Al}_{x}(\mathrm{OH})_{2}\left(\mathrm{NO}_{3}\right)_{x} \cdot n \mathrm{H}_{2} \mathrm{O}$ and $\mathrm{Mg}(\mathrm{OH})_{2}$. Further increase in temperature to $180{ }^{\circ} \mathrm{C}$ yielded larger crystals with sharp edges. The crystallites were crystalline $\mathrm{Mg}(\mathrm{OH})_{2}$ with a distinct hexagonal shape with the edges preferentially directed out of the magnesium alloy. In this study, the substrates themselves were used as the source of magnesium and aluminium to form the nanosheets. This facile and inexpensive approach as a uniform large-scale treatment for the fabrication of nanosheets can be an interesting tool for a variety of applications.

\section{Superhydrophobic surface on magnesium alloy fabricated by microwave plasma-enhanced chemical vapor deposition (MPECVD) and its corrosion resistance}

In this section, we report fabrication and corrosion resistant performance of the superhydrophobic film deposited on magnesium alloy AZ31 by electrochemical measurements. The superhydrophobic film was deposited on magnesium alloy AZ31 by microwave plasma-enhanced chemical vapor deposition (MPECVD). In addition, the chemical stabilities of a superhydrophobic surface on magnesium alloy AZ31 in aqueous solutions of various $\mathrm{pHs}$ were also demonstrated.

Magnesium alloy AZ31 (composition: $2.98 \%$ Al, 0.88\% Zn, 0.38\% Mn, 0.0135\% Si, $0.001 \%$ Cu, $0.002 \% \mathrm{Ni}, 0.0027 \% \mathrm{Fe}$, and the rest is $\mathrm{Mg}$ ) with a size of $10 \times 10 \times 1.5 \mathrm{~mm}$ was used as the substrate. The substrates were ultrasonically cleaned in absolute ethanol for $10 \mathrm{~min}$. Each cleaned substrate was placed on the substrate stage in the MPECVD system. The MPECVD system consisted of a Vycor glass discharge tube attached with a microwave cavity and a deposition chamber made of stainless steel. Superhydrophobic films were then deposited on the substrates using the MPECVD system (Ishizaki et al., 2007; Wu et al., 2002). The chamber of the MPECVD system was evacuated to $5.0 \mathrm{~Pa}$ prior to the deposition. A $2.45-\mathrm{GHz}$ generator supplied microwave power of $250 \mathrm{~W}$, and the raw materials were a gas mixture of trimethylmethoxysilane (TMMOS; $\left.\left(\mathrm{CH}_{3}\right)_{3} \mathrm{SiOCH}_{3}\right)$ and $\mathrm{Ar}$. $\mathrm{Ar}$ gas was required for 
maintaining the microwave discharge. The partial pressures of TMMOS and Ar were kept constant at 35 and $60 \mathrm{~Pa}$, respectively. The deposition time was changed from 10 to $30 \mathrm{~min}$. The substrate temperature remained below $333 \mathrm{~K}$ during the deposition.
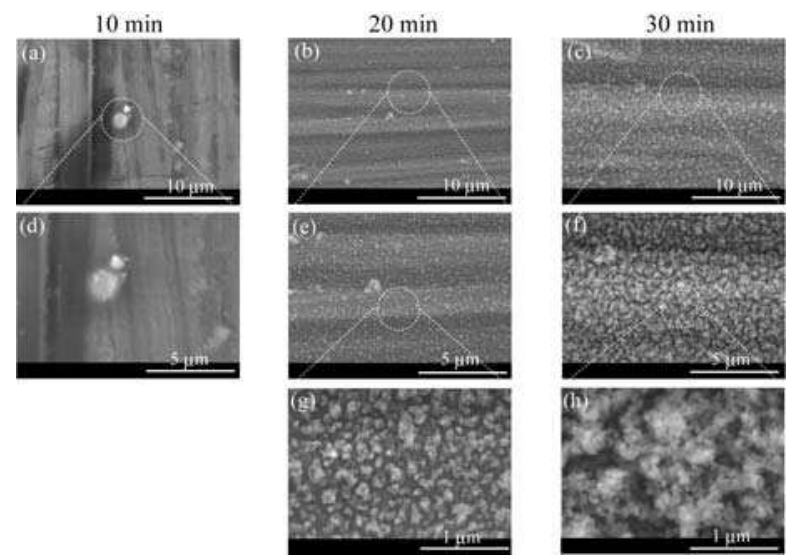

Fig. 1. FE-SEM images of a film on magnesium alloy AZ31 surfaces deposited for (a) 10, (b) 20, and (c) 30 min by the MPECVD process; (d) enlarged FE-SEM image of (a); (e) enlarged FE-SEM image of (b); (f) enlarged FE-SEM image of (c); (g) enlarged FE-SEM image of (e); and (h) enlarged FE-SEM image of (f).topography is important for fabricating a superhydrophobic surface. [Electrochimica Acta., 10.1016/j.electacta.2010.06.064. Copyright @ELSEVIER (2010)]

Figure 1(a), (b), and (c) shows FE-SEM images of the film on magnesium alloy AZ31 surfaces deposited for 10, 20, and 30 min, respectively, by MPECVD. Figure 1 (d), (e), and (f) shows enlarged images of fig. 1 (a), (b), and (c), respectively. The film coverage increases with an increase in preparation time. When the deposition time was less than $10 \mathrm{~min}$, the surface coverage of the film was low and the film surface was smooth compared to those deposited for 20 and $30 \mathrm{~min}$. When the preparation time was prolonged to more than 20 min, the surfaces were covered with the films. The film coverage became higher with an increase in the preparation time. Figure $1(\mathrm{~g})$ and $(\mathrm{h})$ shows enlarged images of fig. 1 (e) and (f), respectively. In the high magnification FE-SEM images (fig. 1 (g) and 1 (h)), aggregated particles were clearly observed. The particles were composed of nanoparticles with sizes of 20-150 nm. Most of these particles would be prepared in a clustering process in the gas phase and condensed on the substrate. The clusters deposited on the magnesium alloy surface, leading to an irregular surface topography composed of granular particles and minute pores with a few hundred nanometers in diameter.

Figure 2 (a), (b), and (c) shows topographic images of the film surface deposited for 10, 20, and $30 \mathrm{~min}$, respectively. As clearly seen in fig. 2, the root mean square roughness of the film-deposited surface increased from 13.7 to $153.5 \mathrm{~nm}$ with an increase in preparation time. These results agree with the results of the FE-SEM images. The increase in the surface roughness would form a porous structure in the film. The porous structures in the film would permit an enhancement of the surface air fraction in the pores and reduce the actual area of rough surface in contact with the water. Thus, such topography provides high water repellency to the surface if the surface were covered with hydrophobic functional groups. 
(a)

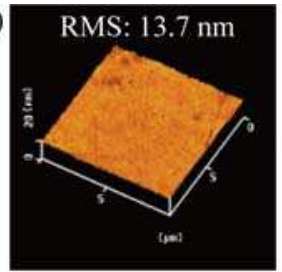

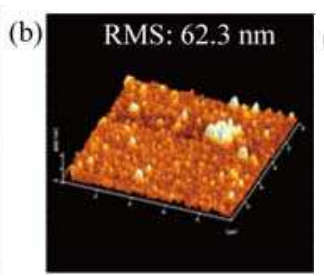

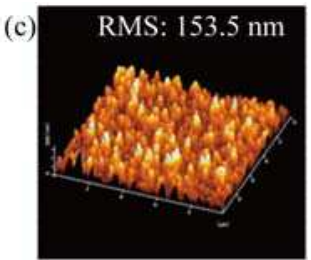

Fig. 2. Topographic images of the film surface deposited for (a) 10, (b) 20, and (c) $30 \mathrm{~min}$. RMS means root mean square roughness of each surface. [Electrochimica Acta., 2010, 55, 7094. Copyright @ELSEVIER (2010)]

Information on the chemical bonding states, chemical composition, and surface functional groups of the film deposited for $30 \mathrm{~min}$ were investigated with FT-IR and XPS. XPS measurements revealed that the film surface consisted of $\mathrm{Si}, \mathrm{O}$, and $\mathrm{C}$ atoms with atomic concentrations of 24.5, 32.9, and 42.6 at \%, respectively. The FT-IR analyses provided information that all the films mainly consisted of $\mathrm{SiOx}$ and $-\mathrm{CH}_{3}$; thus indicating that the surfaces were covered with hydrophobic $-\mathrm{CH}_{3}$ groups. The XPS and FT-IR results agree well with our previous results (Ishizaki et al., 2007; Wu et al., 2004). Next, we estimated the surface wettability of the film deposited by water contact angles measurements.

Figure 3 shows the relationship between water contact angles onto the film surface deposited on magnesium alloy AZ31 and the deposition time. The water contact angles increased with an increase in preparation time. The surface of the film deposited for $10 \mathrm{~min}$ had a water contact angle of c.a. $105^{\circ}$ and was shown to be hydrophobic. In contrast, when the preparation time was over $20 \mathrm{~min}$, the water contact angles of the surfaces were more than $150^{\circ}$, resulting in the superhydrophobic surface. This result indicates that the increase in the static water contact angles has a close relationship with the increase in the surface roughness of the deposited film. In addition, the film coverage also increased with an increase in deposition time. Due to these effects, the wettability of the film coated surface increased greatly, resulting in the superhydrophobic surface.

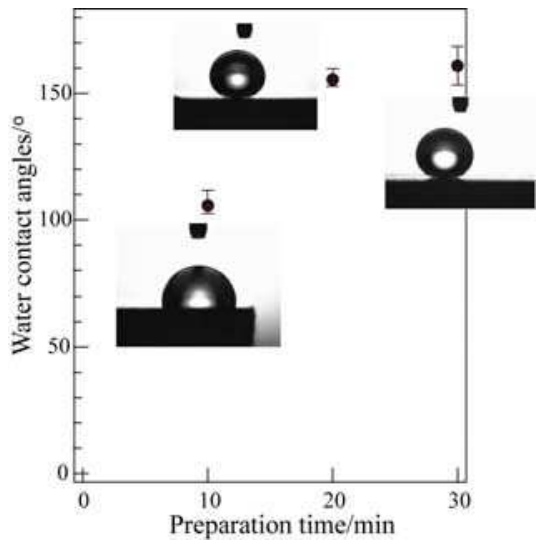

Fig. 3. Relationship between water contact angles on the film surface deposited on magnesium alloy AZ31 and the deposition time. [Electrochimica Acta., 2010, 55, 7094. Copyright @ELSEVIER (2010)] 
All electrochemical measurements were performed in $5.0 \mathrm{wt} \% \mathrm{NaCl}$ aqueous solution, $\mathrm{pH}$ 6.2 , at room temperature, using a computer-controlled potentiostat under open circuit conditions. The superhydrophobic film coated magnesium alloy AZ31 and a platinum plate were used as the working and counter electrodes, respectively. A saturated calomel electrode (SCE) was used as the reference electrode. The reference electrode was set in the close vicinity of the circular window. The superhydrophobic film coated AZ31 substrate was immersed in the $\mathrm{NaCl}$ solution for $30 \mathrm{~min}$, allowing the system to be stabilized, and potentiodynamic polarization curves were subsequently measured with respect to the OCP at a scanning rate of $0.5 \mathrm{mV} / \mathrm{s}$ from -400 to $+800 \mathrm{mV}$. EIS measurements were conducted in the frequency ranges between $0.1 \mathrm{~Hz}$ and $100 \mathrm{kHz}$, with a sinusoidal signal perturbation of $10 \mathrm{mV}$ and five points per decade. All the samples were immersed for $30 \mathrm{~min}$ before all the impedance measurements. The experimental EIS spectra were interpreted based on equivalent electrical analogues using the program Zplot2.0 to obtain the fitting parameters. Figure 4 shows the potentiodynamic polarization curves of the superhydrophobic film coated and bare AZ31. The deposition time of the superhydrophobic film was $30 \mathrm{~min}$. As compared to the corrosion current density $\left(j_{\text {corr }}\right)$ of the bare AZ31 substrate $\left(9.25 \times 10^{-5}\right.$ $\left.\mathrm{A} / \mathrm{cm}^{2}\right)$, that of the coated AZ31 substrate $\left(7.41 \times 10^{-8} \mathrm{~A} / \mathrm{cm}^{2}\right)$ decreased by more than three orders of magnitude. The corrosion potential $\left(E_{\text {corr }}\right)$ of the AZ31 was ca. $-1507 \mathrm{mV}$. Hydrogen evolution dominates at more negative potentials than $E_{\text {corr, }}$ resulting in an increase in the cathodic currents. On the other hand, $E_{\text {corr }}$ of the coated AZ31 substrate is ca. $-1487 \mathrm{mV}$ and is slightly more positive than that of the bare AZ31. A substantial change in $E_{\text {corr }}$ was not detected by the superhydrophobic film. It was reported that silica or zirconia film did not shifted clearly $E_{\text {corr }}$ to positive direction (Tamar \& Mandler, 2008). Our superhydrophobic film consisted of silica and $-\mathrm{CH}_{3}$ groups. Thus, the $E_{\text {corr }}$ would hardly change compared to the bare AZ31. However, the coating of superhydrophobic film decreased significantly both the anodic and cathodic current density. This indicates that the AZ31 substrate coated with the superhydrophobic film has a higher anticorrosion performance than the bare AZ31. The corrosion resistances of the film deposited on magnesium alloy AZ31 and bare AZ31 were estimated by electrochemical impedance spectroscopy. The Nyquist plots obtained from superhydrophobic films (deposition time: 20

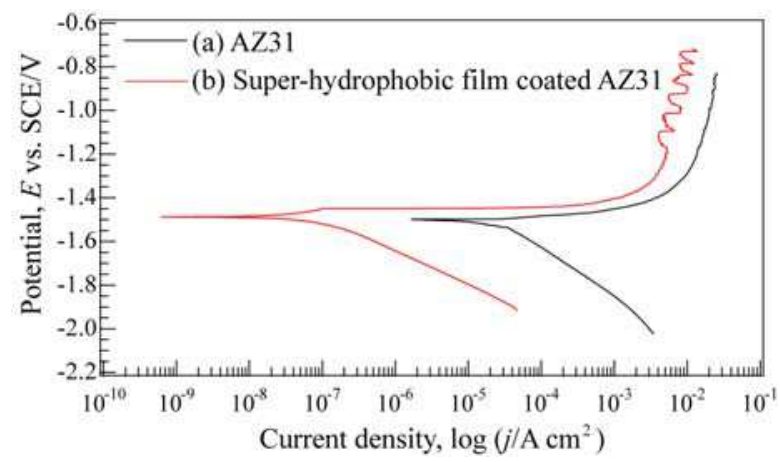

Fig. 4. Potentiodynamic curves of (a) untreated and (b) super-hydrophobic film coated magnesium alloy AZ31. The deposition time of the super-hydrophobic film was $30 \mathrm{~min}$. The scanning rate was $0.5 \mathrm{mV}$ / s. [Electrochimica Acta., 2010, 55, 7094. Copyright @ELSEVIER (2010)] 
and $30 \mathrm{~min}$ ), hydrophobic film (deposition time: $10 \mathrm{~min}$ ), and bare AZ31 after immersion in $5 \mathrm{wt} \% \mathrm{NaCl}$ solution are presented in fig. 5 . The inset of fig. 5 shows the enlarged Nyquist plot. All three surfaces behave quite differently, so we applied different equivalent circuits to fit the Nyquist plots. Three types of equivalent circuits are shown in fig.6.

As shown in fig. 5, the capacitive loops are not perfect semicircles. This phenomenon is known as the dispersing effect (Wu et al., 1999). When the dispersing effect is observed in impedance behavior, the double-layer does not behave as an ideal capacitor. In this case, a constant phase element (CPE) is often used as a substitute for the capacitor in the equivalent circuit to fit the impedance behavior of the electrical double layer more accurately. The CPE is a special element whose value is a function of the angular frequency $\omega$ and whose phase is independent of the frequency. Its admittance $(\mathrm{Y})$ and impedance $(\mathrm{Z})$ are described as follows:

$$
\begin{gathered}
\mathrm{Y}_{\mathrm{CPE}}=\mathrm{Y}_{0}(i \omega)^{n} \\
\mathrm{Z}_{\mathrm{CPE}}=1 / \mathrm{Y}_{0}(i \omega)^{-n}
\end{gathered}
$$

where $\mathrm{Y}_{0}$ is the magnitude of the CPE, $\omega$ is the angular frequency, and $n$ is the exponential term of the CPE.

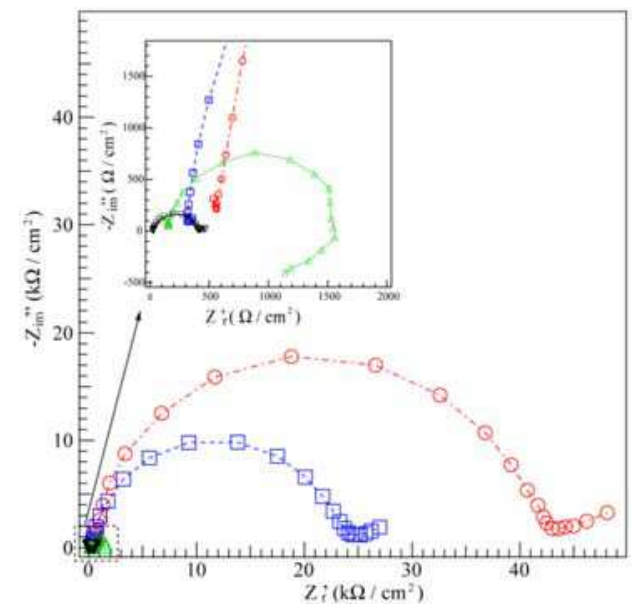

O: Super-hydrophobic film ( $30 \mathrm{~min})$

$\square:$ Super-hydrophobic film (20 min)

$\triangle:$ Hydrophobic film (10 min)

$\nabla:$ Bare magnesium alloy $\mathrm{AZ} 31$

Fig. 5. Nyquist plots obtained from super-hydrophobic films (deposition time: 20 and 30 $\mathrm{min}$ ), hydrophobic film (deposition time: $10 \mathrm{~min}$ ), and bare AZ31 after immersion in $5 \mathrm{wt} \%$ $\mathrm{NaCl}$ solution. The inset shows enlarged Nyquist plots. [Electrochimica Acta., 2010, 55, 7094. Copyright @ELSEVIER (2010)]

Figure 6 (a) shows the equivalent circuit model representing the electrochemical behavior of the bare AZ31 surface, which shows one time constant. In this circuit, $R_{\mathrm{ct}}$ means the charge transfer resistance, $C P E_{\mathrm{dl}}$ is the constant phase element of the electrical double layer, and $R_{\mathrm{s}}$ is the solution resistance. Figure 6 (b) shows the equivalent circuit model representing the electrochemical behavior of the film surface deposited for $10 \mathrm{~min}$. This surface does not show a superhydrophobic property but a hydrophobic property, as shown in fig. $4 . R_{\mathrm{c}}$ is film resistance. The capacitive loop at high frequency can be interpreted as the electrical double layer capacitance $C P E_{\mathrm{dl}}$ in parallel with a charge transfer resistance $R_{\mathrm{ct}}$. An inductance behavior can be seen at the low frequency region. $L$ and $R_{\mathrm{L}}$ are often used to 
explain the inductive loop at low frequency, which originates from adsorbed/desorbed intermediates or other species on the electrode surface (Liu et al., 2007). In the case of the electrode protected with the superhydrophobic film, the equivalent circuit model should consider two time constants in the corresponding impedance spectrum, as shown in fig. 6 (c), since the film has a rough surface with many minute pores. $C_{c}$ would normally be assigned to the capacitance of a surface film, which is based on various factors such as film with the interface reaction between the film and substrate. The parallel combination of $R_{\mathrm{c}}$ which is based on various factors such as film thickness and defect structure. The $R_{\mathrm{ct}}|| C_{\mathrm{dl}}$ elements in Fig. 6 (c) represent the impedance and $C_{c}$ shows impedance with the interface reaction between the electrolytic solution and the film. $R_{\text {air }}$ and $C_{\text {air }}$ are typically associated with the resistance and capacitance of air within a minute pore, respectively. The $R_{\text {air }}|| C_{\text {air }}$ elements were arranged in parallel to above-mentioned these two elements with considering that the many minute pores would be filled with air. By applying this equivalence circuit model in Fig.6 (c) to the Nyquist plots for superhydrophobic film deposited for 20 and 30 min, we obtained better fitting results.

(a)

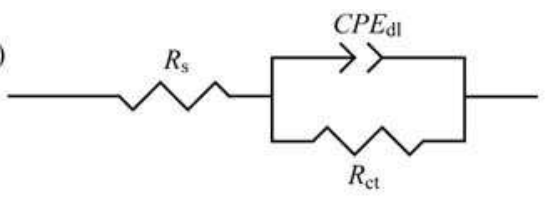

(c)

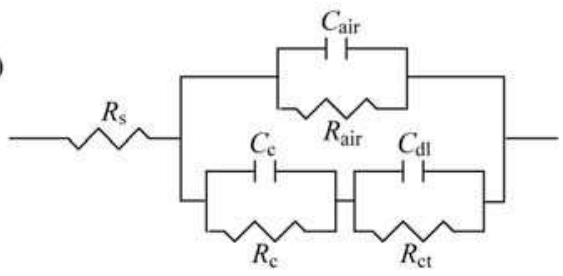

(b)

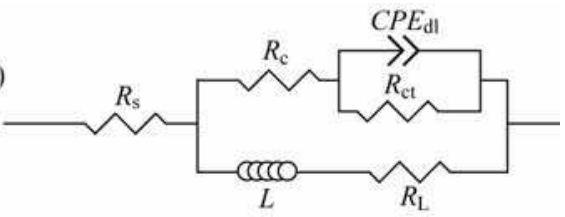

Fig. 6. Equivalent circuits of the studied system (a) bare AZ31 surface, (b) hydrophobic surface (deposition time: $10 \mathrm{~min}$ ), and (c) super-hydrophobic surface (deposition time: 20 and $30 \mathrm{~min}$ ). [Electrochimica Acta., 2010, 55, 7094. Copyright @ELSEVIER (2010)]

As clearly seen in fig. $5, R_{\mathrm{ct}}$ values of the samples estimated in the $5 \mathrm{wt} \% \mathrm{NaCl}$ solution rapidly increased with an increase in the hydrophobicity. This indicates that the hydrophobicity plays an important role in improving the anticorrosion performance of the magnesium alloy. With an increase of the deposition duration the corrosion current density $\left(j_{\text {corr }}\right)$ decreases, whereas the resistance $R_{\mathrm{ct}}$ increases. The double layer capacitances decrease with an increase in the hydrophobicity. The inhibition efficiency (IE\%) can be calculated from the charge transfer resistance as follows (Ma et al., 2002):

$$
\mathrm{IE}=\left(R_{\mathrm{t}}-R_{\mathrm{t} 0}\right) / R_{\mathrm{t}} \times 100
$$

where $R_{\mathrm{t}}$ is the charge transfer resistance of the film-deposited AZ31 and $R_{\mathrm{t} 0}$ is the resistance of the bare AZ31. The IE of the film deposited for 10, 20, and $30 \mathrm{~min}$ were estimated to be $71.4,98.3$, and $99.1 \%$, respectively. The IE considerably increased with an increase in the hydrophobicity of the film surface. This indicates that our superhydrophobic film effectively suppressed the progress of the corrosion reaction. Figure 7 presents the evolution of the 
impedance spectra of the superhydrophobic film coated AZ31 after different times of immersion in $5 \mathrm{wt} \% \mathrm{NaCl}$ solution. As clearly seen in fig. 7, the capacitive loops at high and medium frequencies and tail at low frequencies are observed. The capacitive loops can be attributed to the charge transfer of the corrosion process and the tail might be associated with a diffusion process across the corrosion layer (Feliu et al., 1990). The capacitive loops decreased gradually with an increase in the immersion time. This indicates that the anticorrosion performance of the superhydrophobic film is lowered gradually with immersion time. The lowering of the anticorrosion performance might be due to the localized corrosion. Once local corrosion begins at the film surface, the hydroxide ions are produced in the $\mathrm{NaCl}$ solution. As a result, the $\mathrm{pH}$ in the vicinity of superhydrophobic film increases locally. Due to the local $\mathrm{pH}$ change, the superhydrophobic film might dissolve locally because SiOx components in our superhydrophobic film could be dissolved as $\mathrm{HSiO}_{3}$ - ion species in the solution at $\mathrm{pH}$ ranging from 10 to 12 (Pourbaix, 1974). Thus, the diameter of the capacitive loops that is closely related to the corrosion rate could decrease. However, the charge transfer of the superhydrophobic film coated AZ31 after immersion in $5 \mathrm{wt} \% \mathrm{NaCl}$ solution for $24 \mathrm{~h}$ is much greater than that of uncoated AZ31. This indicates that the superhydrophobic film can improve the anticorrosion of magnesium alloy in the $\mathrm{NaCl}$ solution.

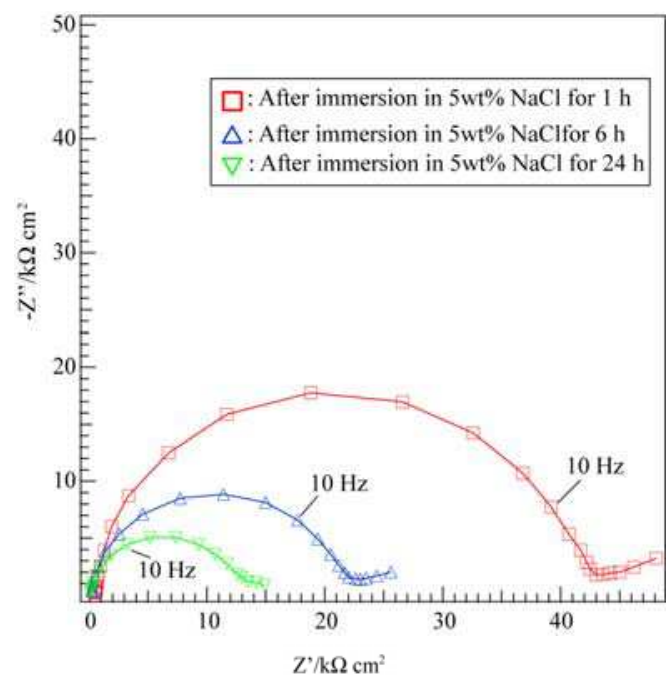

Fig. 7. Evolution of Nyquist plots of the super-hydrophobic film coated magnesium alloy AZ31after immersion in $5 \mathrm{wt} \% \mathrm{NaCl}$ aqueous solution for (a) $1 \mathrm{~h}$, (b) $6 \mathrm{~h}$, and (c) $24 \mathrm{~h}$. [Electrochimica Acta., 2010, 55, 7094. Copyright @ELSEVIER (2010)]

From a theoretical point of view, to inhibit corrosion, it would be very effective to minimize the wetted area on a solid surface immersed in the $\mathrm{NaCl}$ aqueous solution. A superhydrophobic surface would be a means to achieve this since the superhydrophobic surface has many roughness structures that could trap air at the solid-liquid interface. Minimizing the wetted area on a solid surface might be achieved if an air layer formed on the superhydrophobic surface could be stabilized within the roughness grooves. Quéré et al. demonstrated that the air entrapment state would be metastable for the following conditions (Bico et al., 2002): 


$$
\cos \theta \leq\left(f_{1}-1\right) /\left(\gamma-f_{1}\right)
$$

where $f_{1}$ is the fraction of the solid/liquid interface below the drop in contact with the solid, $\gamma$ is the roughness ratio of the surface, and $\theta$ is the contact angle. According to equation (8), if $\theta$ is higher than $90^{\circ}$, the air would be trapped below the liquid (within the surface). After EIS measurement, the water contact angle of superhydrophobic surface was still c.a. $141^{\circ}$. This proves that the air layer was stabilized within the roughness grooves in the process of the whole experiment. Our superhydrophobic treatment could reduce considerably the probability of adsorption of aggressive ion species $\left(\mathrm{Cl}^{-}\right)$to the superhydrophobic film deposited magnesium alloy AZ31, and the AZ31 surface was thus protected. Moreover, our superhydrophobic film has great roughness structures, as shown in figs. 1 and 2. Such roughness structures had many minute spaces and thus can easily trap air within the minute spaces between the roughness structures, preventing the most part of the $\mathrm{Cl}$ - ions from reaching the bare AZ31 surface.

We successfully deposited a superhydrophobic film on magnesium alloy AZ31 through the MPECVD process. The film surface showed a water contact angle of more than $150^{\circ}$, that is, superhydrophobicity. The anticorrosion resistance of the deposited film was estimated by potentiodynamic and EIS measurement.

\section{Rapid formation of superhydrophobic surface on magnesium alloy coated with cerium oxide film and its chemical stability}

In this section, we report a simple immersion process at room temperature for the fabrication of superhydrophobic surface on magnesium alloy. The chemical stabilities of the superhydrophobic surfaces on magnesium alloy were also examined from view points of durability and corrosion resistance.

Magnesium alloy AZ31 (composition: 2.98\% Al, 0.88\% Zn, 0.38\% Mn, 0.0135\% Si, $0.001 \% \mathrm{Cu}$, $0.002 \% \mathrm{Ni}, 0.0027 \% \mathrm{Fe}$, and the rest is $\mathrm{Mg}$ ) with a thickness of $1.5 \mathrm{~mm}$ was used as the substrate. The substrates were ultrasonically cleaned in absolute ethanol for $10 \mathrm{~min}$. After the cleaning, the substrates were dried with inert Ar gas. The cleaned magnesium alloy substrates were immersed in an acidic solution containing $0.05 \mathrm{M}$ cerium nitrate $\left(\mathrm{Ce}\left(\mathrm{NO}_{3}\right)_{2}\right)$ with $\mathrm{pH}$ experimentally measured to be c.a. 4.5 at room temperature. The solution was agitated with magnetic stirrer at a rotation of $100 \mathrm{rpm}$ during the immersion. The immersion time was changed from 0.5 to $20 \mathrm{~min}$. After immersion, the samples were thoroughly washed in absolute ethanol. Finally, the washed samples were immersed in $40 \mathrm{ml}$ of toluene solution containing $400 \mu \mathrm{l}$ of FAS $\left(\mathrm{CF}_{3}\left(\mathrm{CF}_{2}\right)_{7} \mathrm{CH}_{2} \mathrm{CH}_{2} \mathrm{Si}\left(\mathrm{OCH}_{3}\right)_{3}\right)$ and $40 \mu \mathrm{l}$ of tetrakis(trimethylsiloxy)titanium $\left.\left(\left(\mathrm{CH}_{3}\right)_{3} \mathrm{SiO}\right)_{4} \mathrm{Ti}\right)$ (TTST) for $30 \mathrm{~min}$. The TTST molecules were used as catalysis to promote hydrolysis and/or polymerization of FAS molecules.

Figure 1 shows FE-SEM images of the sample surfaces after immersion in cerium nitrate aqueous solution for (a) 0.5, (b) 1, (c) 3 (d) 5, (e) 10, and (f) $20 \mathrm{~min}$. After $0.5 \mathrm{~min}$ of immersion, the surface of the magnesium alloy was covered with a coating film with islandlike particles. However, the coverage was not complete. After $1 \mathrm{~min}$ of immersion, the substrate surface was covered with almost complete coating on which some microcracks were formed (Fig. 1(b)). When the immersion time was prolonged to more than $3 \mathrm{~min}$, the coating became thick enough to cover the substrate. On the other hand, cracks with larger crack-width were also formed (Fig. 1(c)). These cracks divided whole coating into pieces separated by relatively large cracks. Several relatively small microcracks were observed 
within each piece, as can be seen in Fig. 1 (d)-(f). These cracks in the coating film could be formed after withdrawing the sample from the solution due to the shrinkage in volume. This shrinkage occurred by the evaporation of the water molecules containing in the coating film, allowing cracks to form. Figure $1(\mathrm{~g})$, (h), and (i) shows the enlarged versions of the FESEM images shown in Fig. 1(b), (d), and (f), respectively. All the samples exhibit nanosheets that are aligned at fairly inclined angles with respect to the surface. When the treatment time was less than $1 \mathrm{~min}$, the nanosheets were locally formed on the surfaces. In contrast, after treatment for over $3 \mathrm{~min}$, the nanosheets were observed to be vertically aligned over the entire substrate surface. The vertically aligned nanosheets became dense as the treatment time increased. The nanosheets exhibit an edge length in the range of approximately 200$1000 \mathrm{~nm}$ and a thickness of 20-50 nm. The aggregation of the nanosheets could lead to an irregular surface topography with nanoscale pores composed of valleys and hills. Such surface texture is suitable for fabricating a superhydrophobic surface. An increase in the immersion time to 20 min was found to result in the formation of compact and continuous nanosheets due to an increase in nucleation and growth periods. Figure 2 shows XRD pattern of the obtained sample after immersion in cerium nitrate aqueous solution for 20 min. Some broad and sharp peaks were clearly observed. The sharp peaks were attributed to magnesium alloy substrate, while the broad peaks were assigned to cerium oxide with cubic system, which are indexed based on the JCPDS data (Card No. 43-1002). The five broad peaks at approximately $2 \theta=28.5,33.1,47.5,56.3$ and $76.7^{\circ}$ were assigned to the $111,200,220$, 311, and 331 diffraction peaks of cerium oxide with the cubic phase. These broad peaks also confirm the existence of nanosized grains in the major overlay. This agrees well with results of FE-SEM observation.
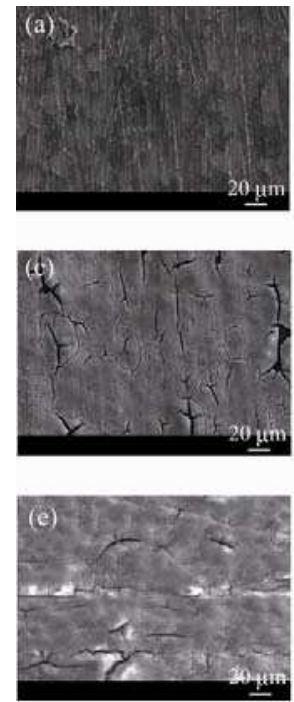
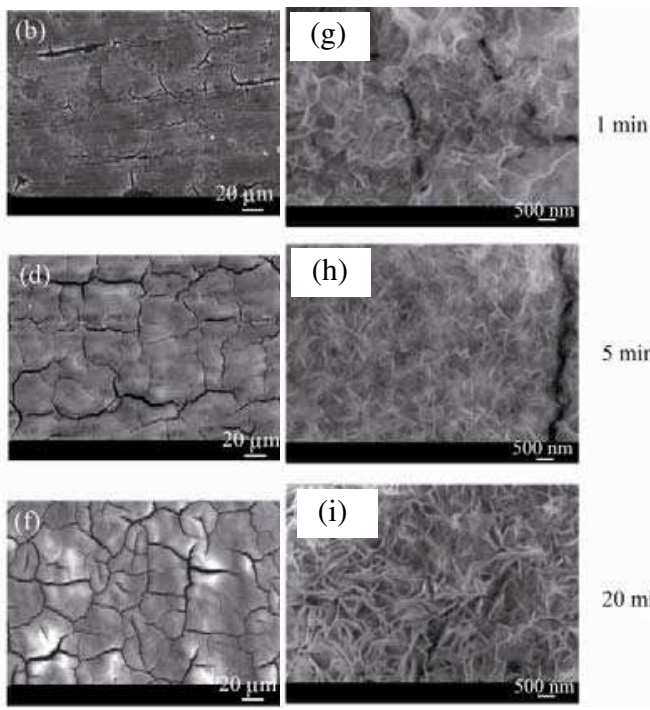

$5 \mathrm{~min}$

$20 \mathrm{~min}$

Fig. 1. FE-SEM images of the sample surfaces after immersing in cerium nitrate aqueous solutions at room temperature for (a) 0.5, (b) 1, (c) 3, (d) 5, (e) 10, and (f) $20 \mathrm{~min}$. (g) Enlarged versions (b). (h) Enlarged versions in (d). (i) Enlarged versions in (f). [Reprinted with permission, Langmuir. 26, 9749, 2010. Copyright @American Chemical Society (2010)] 


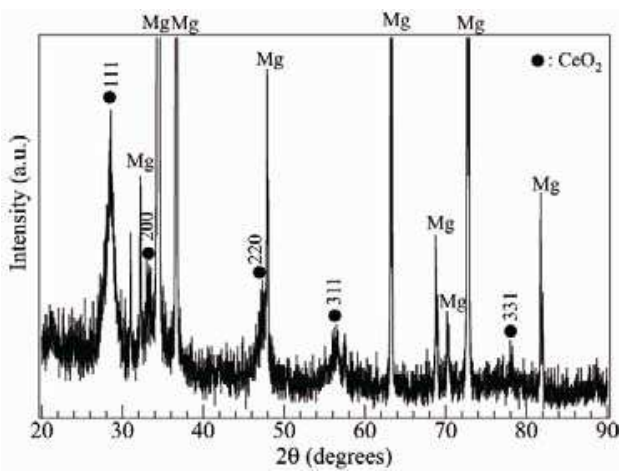

Fig. 2. XRD pattern of the obtained sample after immersion in cerium nitrate aqueous solution for $20 \mathrm{~min}$. [Reprinted with permission, Langmuir. 26, 9749, 2010. Copyright @American Chemical Society (2010)]

Figure 3 (a) shows a cross sectional TEM image of the sample after immersion in cerium nitrate aqueous solution for $20 \mathrm{~min}$. It is known that the magnesium alloy AZ31 surface had an oxide layer with a thickness of c.a. $50 \mathrm{~nm}$ (Liu \& Fang, 2005). The existence of the oxide layer supports that the magnesium alloy is active when exposed to atmosphere. Our film fabricated had a thickness of c.a. $2 \mu \mathrm{m}$ and exhibited a three layered structure with a slightly porous layer (marked as 1 in Fig. 3 (a)) as an under layer intimately in contact with the magnesium alloy substrate and a compact layer (marked as 2 in Fig. 3 (a)) as an intermediate layer, and a fibrous layer (marked as 3 in Fig. 3 (a)) as the major top layer. The composition of the each layer was measured by EDAX analyses. The slightly porous layer showed that the atomic concentration of $\mathrm{Mg}, \mathrm{O}, \mathrm{Al}$, and $\mathrm{Zn}$ was 81.14, 14.03, 3.72, and 1.11 at\%, respectively, suggesting that this layer was primarily a mixture of magnesium and
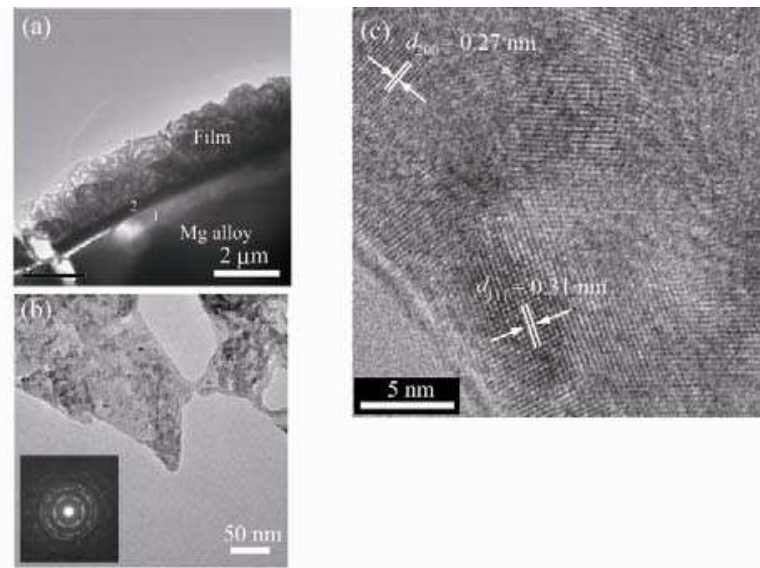

Fig. 3. (a) Cross-sectional TEM image of the sample after immersion in cerium nitrate aqueous solution for $20 \mathrm{~min}$. (b) TEM image of the tip of the fibrous layer. The inset shows the SAED pattern. (c) High-resolution TEM image of the $\mathrm{CeO}_{2}$ nanosheet. [Reprinted with permission, Langmuir. 26, 9749, 2010. Copyright @American Chemical Society (2010)] 
aluminum hydroxides and oxides. On the other hand, except for magnesium, zinc and oxide, cerium was detected in both the compact and fibrous layer. Both layers could be mixtures of cerium and magnesium hydroxides and oxides. It should be noted that the fibrous layer greatly contributed to the greater coating thickness, although this layer was formed discontinuously. The discontinuity of the fibrous layer correlated well with the results of the SEM observation. Figure 3 (b) shows the high magnified TEM image of the tip of the fibrous layer. The high magnified TEM image revealed that the nanosheet comprised of many minute nanosized crystallinity. The selected area electron diffraction (SAED) patterns exhibit some rings corresponding to the [111], [200], [220], [311] and [331] planes of $\mathrm{CeO}_{2}$.

These patterns are consistent with the XRD patterns. The discrete spots on the rings suggest that the crystals were of good crystallinity. Figure 3 (c) shows high-resolution TEM image of the nanosheet. Lattice fringes with interplanar spacings, $d_{111}=0.31$ and $d_{200}=0.27 \mathrm{~nm}$ can be clearly observed and are consistent with the cubic phase.

The control of the microstructures was achieved by varying the immersion time. To fabricate superhydrophobic surface, FAS coating was performed on the $\mathrm{CeO}_{2}$ nanosheets by immersing it in the toluene solution containing FAS and TTST molecules for $30 \mathrm{~min}$. The wetting properties were evaluated by water contact angle measurements of the samples surfaces fabricated by immersion in cerium nitrate aqueous solution for $20 \mathrm{~min}$ and the samples obtained after FAS coating. Figure 4 (a) shows a shape of water droplet on the asprepared surface composed of $\mathrm{CeO}_{2}$ nanosheets. When a water droplet was dropped on the as-prepared surface, it spreaded onto the sample surface very quickly, indicating the superior super-hydrophilic property of the sample surface. This is in line with the very low contact angle, $3 \pm 2^{\circ}$, of the as-prepared sample surface composed of $\mathrm{CeO}_{2}$ nanosheets. Such a small contact angle is attributed to the presence of $-\mathrm{OH}$ groups on the surface of the $\mathrm{CeO}_{2}$ nanosheets, leading to superhydrophilicity. However, the sample surface became superhydrophobic after simply immersing the sample in toluene solution containing FAS and TTST for 30 min. Figure 4 (b) shows a water droplet behavior on the $\mathrm{CeO}_{2}$ nanosheets surface after FAS coating. The static water contact angle of these modified sample surface was found to be $155 \pm 2^{\circ}$, clearly revealing that the surface changed from superhydrophilicity to superhydrophobicity. Figure 4 (c) shows a digital photograph image of a shape of water droplets on the superhydrophobic surface. The digital photograph image of water droplets with uniform size on the surface of the FAS modified $\mathrm{CeO}_{2}$ nanosheets gives a direct demonstration of superhydrophobicity of the treated surface. From these results, we
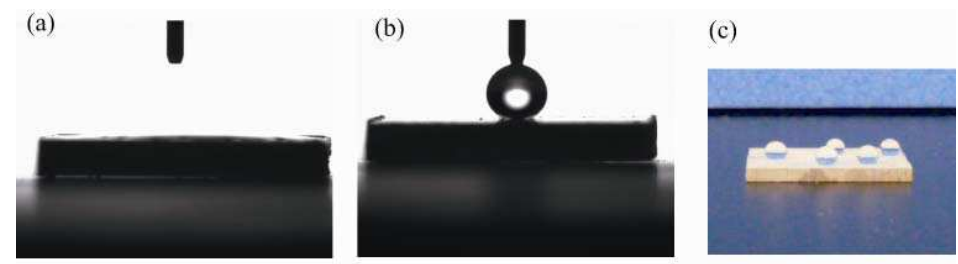

Fig. 4. (a) Shape of water droplet on the as-prepared surface composed of $\mathrm{CeO}_{2}$ nanosheets. (b) Water droplet behavior on the $\mathrm{CeO}_{2}$ nanosheets surface after FAS coating. (c) Digital photograph image of a shape of water droplets on the super-hydrophobic surface. [Reprinted with permission, Langmuir. 26, 9749, 2010. Copyright @American Chemical Society (2010)] 
concluded that the FAS coating by catalyst-assisted immersion process was successfully achieved and the process of FAS coating was completed within $30 \mathrm{~min}$. Moreover, the effects of the microstructures based on $\mathrm{CeO}_{2}$ nanosheets on wetting properties were investigated by dynamic contact angle measurements. Figure 5 shows the relationship between advancing and receding water contact angles and immersion time in cerium nitrate aqueous solutions. All the samples for dynamic contact angle measurements were separately prepared as follows. First, they were immersed in the cerium nitrate aqueous solution for set time. Next, the $\mathrm{CeO}_{2}$ coated samples were modified with FAS molecules. As clearly seen in Fig. 5, the advancing and receding contact angles gradually increased with an increase in the immersion time. The water contact angles hysteresis (the difference between the advancing and receding water contact angles) also become small with an increase in the immersion time. It is known that the surface wettability is controlled by the chemical composition and surface roughness of solids (Liu \& Fang, 2005). The water contact angle of a smooth surface can reach to c.a. $120^{\circ}$, but on the micropatterned surface or hierarchical structures, the water contact angles can reach to maximum value of c.a. $178^{\circ}$ (Hosono et al., 2005). This suggests that the fabrication of the hierarchical structures is a crucial factor for the fabrication of superhydrophobic surface (Zhu et al., 2006). Our surface fabricated by the $\mathrm{CeO}_{2}$ film has hierarchical structures. The rough surface can trap a large fraction of air within the micro- and nanotextured surfaces created between the nanosheets. The trapped air can greatly increase the air-liquid interface, which prevents the water droplets from penetrating into the grooves of the surfaces. Our surface fabricated showed the advancing water contact angle of more than $150^{\circ}$ and the contact angle hysteresis of less than $10^{\circ}$. These results support that the water droplets do not penetrate into the grooves. Thus, the microand nanostructures based on the $\mathrm{CeO}_{2}$ nanosheets not only enhance the surface hydrophobicity but also reduce the contact angle hysteresis by decreasing the contact area between solid and liquid at their interface and the continuity of the three-phase contact line at the solid-liquid interface.

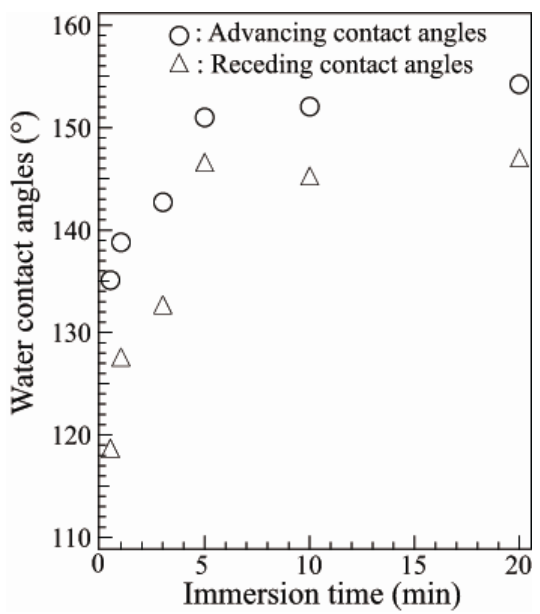

Fig. 5. Advancing and receding water contact angles of the sample surfaces after FAS coating as a function of immersion time in cerium nitrate aqueous solutions. [Reprinted with permission, Langmuir. 26, 9749, 2010. Copyright @American Chemical Society (2010)] 
To apply the superhydrophobic surface to industrial fields, it is very important to reveal the chemical stability of the superhydrophobic film in the aqueous solution. Chemical stability of superhydrophobic surface on magnesium alloy AZ31 was estimated by measuring static water contact angles of the superhydrophobic surfaces after immersing in aqueous solutions at various $\mathrm{pHs}$ for constant times. Figure 6 shows changes in static contact angles of the sample surface fabricated by immersion in cerium nitrate aqueous solution for $20 \mathrm{~min}$ and FAS coating for $30 \mathrm{~min}$ as a function of immersion time in aqueous solutions at $\mathrm{pH}=4.0,7.0$, and 10.0, that is, acidic, neutral, and alkaline solutions. All the plots in fig. 6 show the averaged values of water contact angles measured at different five points. The error bars for each plot mean maximum and minimum water contact angles, which were measured at different points on same sample. For all the solutions, the static water contact angles of the superhydrophobic surfaces gradually decreased with time evolution. This indicates that the density of the hydrophobic functional groups on the surface could be reduced by immersing the samples in each $\mathrm{pH}$ solution. The static water contact angles decreased to be in the ranges of c.a. $140 \pm 2$ to $150 \pm 2^{\circ}$ within $60 \mathrm{~min}$ after immersion in each $\mathrm{pH}$ 's solution. However, the static water contact angles after the immersion for 60 to 360 min hardly changed. The averaged static water contact angles of the superhydrophobic surfaces after the immersion in the solutions at $\mathrm{pH}=4,7$, and 10 for $24 \mathrm{~h}$ were estimated to be $139.7 \pm 2^{\circ}$, $140.0 \pm 2^{\circ}$, and $145.7 \pm 2^{\circ}$, respectively.

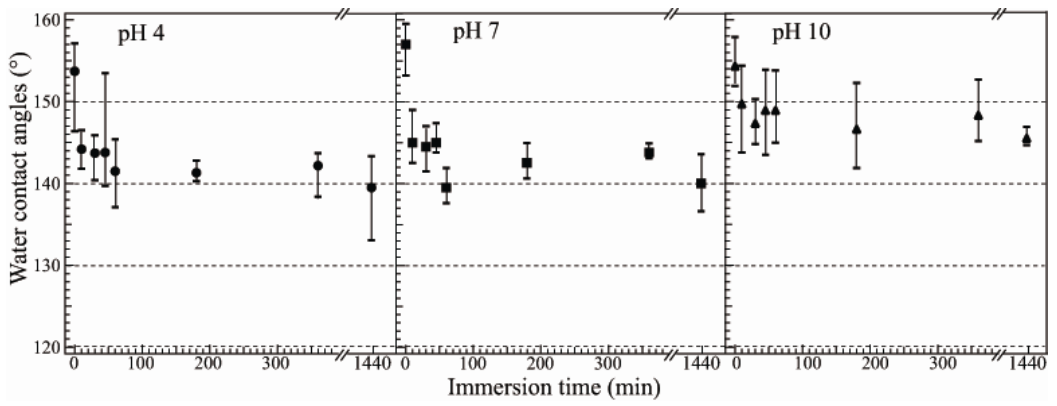

Fig. 6. Changes in static contact angles of the sample surfaces as a function of immersion time in aqueous solutions at $\mathrm{pH}=4.0,7.0$, and 10.0. The super-hydrophobic surfaces were fabricated by immersion in cerium nitrate aqueous solution for $20 \mathrm{~min}$ and FAS coating for $30 \mathrm{~min}$. All the plots show the averaged values of water contact angles measured at different five points on same samples. The error bars for each plot mean maximum and minimum water contact angles. [Reprinted with permission, Langmuir. 26, 9749, 2010. Copyright @American Chemical Society (2010)]

Figure 7 shows potentiodynamic curves of (a) bare magnesium alloy and (b) superhydrophobic surface on magnesium alloy. The corrosion potential, $E_{\text {corr, }}$ of the superhydrophobic surface was more positive than that of bare magnesium alloy. The shift of the $E_{\text {corr }}$ in the positive direction could be linked to an improvement of the protective properties of the superhydrophobic film formed on the AZ31 magnesium alloy. The corrosion current density, $j_{\text {corr }}$, of the superhydrophobic film coated AZ31 $\left(8.11 \times 10^{-7}\right.$ $\mathrm{A} / \mathrm{cm}^{2}$ ) decreased by more than one order of magnitude as compared to that of the uncoated one $\left(6.71 \times 10^{-6} \mathrm{~A} / \mathrm{cm}^{2}\right)$. These results indicate that the superhydrophobic film has good corrosion resistance. 


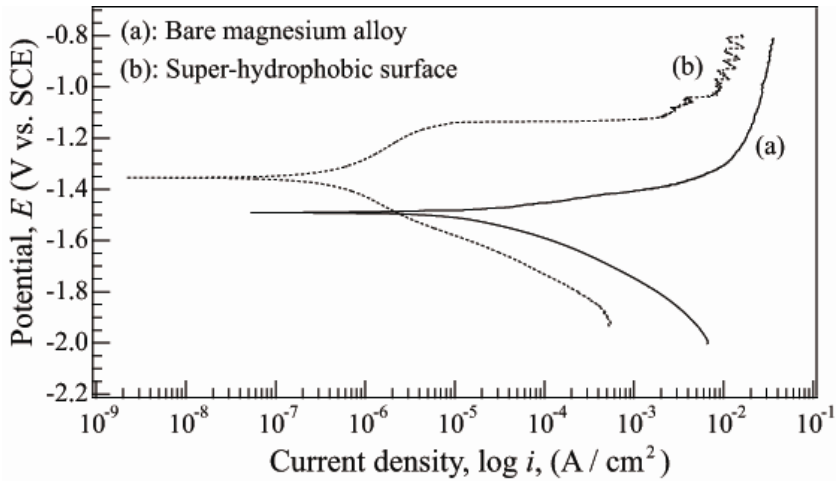

Fig. 7. Potentiodynamic curves of (a) bare magnesium alloy and (b) super-hydrophobic surface on magnesium alloy. The scanning rate was $0.5 \mathrm{mV} / \mathrm{s}$. [Reprinted with permission, Langmuir. 26, 9749, 2010. Copyright @American Chemical Society (2010)]

We have developed a facile, simple, and time-saving method to create superhydrophobic surface on magnesium alloy by a simple immersion process. The FAS modified $\mathrm{CeO}_{2}$ nanosheets surface showed a static contact angle of more than $150^{\circ}$, resulting in the formation of superhydrophobic surface. The contact angles hysteresis decreased with an increase in the immersion time in the cerium nitrate aqueous solution. The shortest processing time for the fabrication of the superhydrophobic surface was within $40 \mathrm{~min}$. Chemical stability of the superhydrophobic surface on magnesium alloy AZ31 was investigated. In addition, the chemical stability of the superhydrophobic surface in the solutions at $\mathrm{pH}$ ranging from 1 to 14 was also examined. Moreover, the corrosion resistance of the superhydrophobic surface on the magnesium alloy was investigated using electrochemical measurements.

\section{Conclusion and outlook}

In this chapter, we showed experimental studies on the formation of hierarchical structures composed of crystalline nanosheets and two types of superhydrophobic surfaces by surface treatment. The hierarchical structures formed on magnesium alloy could be used as a template of superhydrophobic surface. All electrochemical measurements revealed that the superhydrophobic treatments by MPECVD process greatly improved the corrosion resistance of magnesium alloy. Water contact angle measurements showed that the superhydrophobic film had highly chemical stability to acidic and neutral aqueous solution. Finally, we reported a facile, simple, and time-saving method to create superhydrophobic surface on magnesium alloy by a simple immersion process at room temperature. The superhydrophobic surface showed highly chemical stability to the solution at $\mathrm{pH}$ ranging from 1 to 14 . The electrochemical potentiodynamic measurements revealed that the superhydrophobic film have good corrosion resistance. These results suggest that superhydrophobic treatments would be a promising mean for improving greatly the corrosion resistance of magnesium and its alloys.

Magnesium and its alloys are one of the most promising materials for reducing vehicle weight, lowering fuel consumption and reducing $\mathrm{CO}_{2}$ emission. An extremely low corrosion resistant property of the magnesium alloys, however, restricts larger scale use toward the 
various applications. At present, though a great deal of work of academic and commercial interest on surface treatments of magnesium alloys has been carried out, still more remains to be done in order to improve considerably their corrosion resistances. In the future, we believe work on the development of surface treatments to improve considerably their corrosion resistances will continue to expand rapidly.

\section{References}

Acatay, K.; Simsek, E.; Ow-Yang, C. \& Menceloglu, Y. Z. (2004). Tunable, superhydrophobically stable polymeric surfaces by electrospinning. Angewandte Chemie International Edition, 43, 39, 5210-5213, 1521-3773.

Barchiche, C. -E.; Rocca, E.; Juers, C.; Hazan, J. \& Steinmetz, J. (2007). Corrosion resistance of plasma-anodized AZ91D magnesium alloy by electrochemical methods. Electrochimica Acta, 53, 2, 417-425, 0013-4686.

Baril, G.; Galicia, G.; Deslouis, C.; Pebere, N.; Tribollet, B. \& Vivier, V. (2007). An impedance investigation of the mechanism of pure magnesium corrosion in sodium sulfate solutions. Journal of The Electrochemical Society, 154, 2, C108-C113, 0013-4651.

Barthlott, W. \& Neinhuis, C. (1997). Purity of the sacred lotus, or escape from contamination in biological surfaces. Planta, 202, 1, 1-8, 0032-0935.

Benesi, H. A. (1959). Infrared spectrum of $\mathrm{Mg}(\mathrm{OH})_{2}$. Journal of Chemical Physics, 30, 3, 852, 0021-9606.

Bico, J.; Thiele, U. \& Quéré, D. (2002). Wetting of textured surfaces. Colloids and Surfaces A: Physicochemical and Engineering Aspects, 206, 1-3, 41-46, 0927-7757.

Callies, M. \& Quere, D. (2005). On water repellency. Soft Matter, 1, 1, 55-61, 1744-683X.

Cavani, F.; Trifiro, F. \& Vaccari, A. (1991). Hydrotalcite-type anionic clays: Preparation, properties and applications. Catalysis Today, 11, 2, 173-301, 0920-5861.

Chen, D. \& Gao, L. (2004). Novel morphologies of nickel sulfides: nanotubes and nanoneedles derived from rolled nanosheets in a w/o microemulsion. Journal of Crystal Growth, 262, 1-4, 554-560, 0022-0248.

Chen, D. \& Gao, L. (2005). A new and facile route to ultrafine nanowires, superthin flakes and uniform nanodisks of nickel hydroxide. Chemical Physics Letters, 405, 1-3, 159164, 0009-2614.

Chen, H.; Zhang, F.; Fu, S. \& Duan, X. (2006). In situ microstructure control of oriented layered double hydroxide monolayer films with curved hexagonal crystals as superhydrophobic materials. Advanced Materials, 18, 23, 3089-3093, 0935-9648.

Chisem, I. C. \& Jones, W. (1994). Ion-exchange properties of lithium aluminium layered double hydroxides. Journal of Materials Chemistry, 4, 11, 1737-1744, 0959-9428.

Feliu, S.; Galvan, J. C. \& Morcillo, M. (1990). The charge transfer reaction in Nyquist diagrams of painted steel. Corrosion Science, 30, 10, 989-998, 0010-938X.

Gray, J. E. \& Luan, B. (2002). Protective coatings on magnesium and its alloys - a critical review. Journal of Alloys and Compounds, 336, 1-2, 88-113, 0925-8388.

Guo, Z.; Zhou, F.; Hao, J. \& Liu, W. (2005). Stable biomimetic super-hydrophobic engineering materials. Journal of the American Chemical Society, 127, 45, 15670-15671, $0002-7863$.

Haycock, D. E.; Kasrai, M.; Nicholls, C. J. \& Urch, D. S. (1978). The electronic structure of magnesium hydroxide (brucite) using X-ray emission, X-ray photoelectron, and 
auger spectroscopy. Journal of the Chemical Society, Dalton Transactions, 1978, 11, 1791-1796, 1472-7773.

He, T.; Wang, Y.; Zhang, Y.; Iv, Q.; Xu, T. \& Liu, T. (2009). Super-hydrophobic surface treatment as corrosion protection for aluminum in seawater. Corrosion Science, 51, 8, 1757-1761.

Hosono, E.; Fujihara, S.; Honma, I. \& Zhou, H. (2005). Superhydrophobic perpendicular nanopin film by the bottom-up process. Journal of the American Chemical Society, 2005, 127, 39, 13458-13459, 0002-7863.

Huang, L.; Lau, S. P.; Yang, H. Y.; Leong, E. S. P.; Yu, S. F. \& Prawer, S. (2005). Stable superhydrophobic surface via carbon nanotubes coated with a $\mathrm{ZnO}$ thin film. The Journal of Physical Chemistry B, 109, 16, 7746-7748, 1520-6106.

Ishizaki, T.; Saito, N.; Inoue, Y.; Bekke, M. \& Takai, O. (2007). Fabrication and characterization of ultra-water-repellent alumina-silica composite films. Journal of Physics D: Applied Physics, 40, 1, 192-197, 0022-3727.

Ishizaki, T.; Cho, S.P.; Saito, N. (2009). Morphological control of vertically self-aligned nanosheets formed on magnesium alloy by surfactant-free hydrothermal synthesis. CrystEngComm, 11, 2338-2343, 1466-8033.

Ishizaki, T.; Saito, N. (2010). Rapid formation of a superhydrophobic surface on a magnesium alloy coated with a cerium oxide film by a simple immersion process at room temperature and its chemical stability. Langmuir, 26, 9749-9755, 0743-7463.

Ishizaki, T.; Saito, N.; Saito, N.; Takai O. (2010). Corrosion resistance and chemical stability of super-hydrophobic film deposited on magnesium alloy AZ31 by microwave plasma-enhanced chemical vapor deposition. Electrochimica Acta, 2010, 55, 7094.

Kannan, S.; Velu, S.; Ramkumar, V. \& Swamy, C. S. (1995). Synthesis and physicochemical properties of cobalt aluminium hydrotalcites. Journal of Materials Science, 30, 6, 14621468, 0022-2461.

Khorasani, M.; Mirzadeh, H. \& Kermani, Z. (2005). Wettability of porous polydimethylsiloxane surface: morphology study. Applied Surface Science, 242, 3-4, 339-345, 0169-4332.

Kloprogge, J. T.; Hickey, L. \& Frost, R. L. (2005). The effect of varying synthesis conditions on zinc chromium hydrotalcite: a spectroscopic study. Materials Chemistry and Physics, 89, 1, 99-109, 0254-0584.

Kuma, K.; Paplawsky, W.; Gedulin, B. \& Arrhenius, G. (1989). Mixed-valence hydroxides as bioorganic host minerals. Origins of Life and Evolution of Biospheres, 19, 5, 573-602, 0169-6149.

Labajos, F. M.; Rives, V. \& Ulibarri, M. A. (1992). Effect of hydrothermal and thermal treatments on the physicochemical properties of $\mathrm{Mg}-\mathrm{Al}$ hydrotalcite-like materials. Journal of Materials Science, 27, 6, 1546-1552, 0022-2461.

Leite, E. R.; Giraldi, T. R.; Pontes, F. M.; Longo, E.; Beltrán, E. A. \& Andrés, J. (2003). Crystal growth in colloidal tin oxide nanocrystals induced by coalescence at room temperature. Applied Physics Letters, 83, 8, 1566-1568, 0003-6951.

Lejeune, M.; Lacroix, L.M.; Bretagnol, F.; Valsesia, A.; Colpo, P. \& Rossi, F. (2006). Plasmabased processes for surface wettability modification. Langmuir, 22, 7, 3057-3061, 0743-7463. 
Lian, J. S.; Li, G. Y.; Niu, L. Y.; Gu, C. D.; Jiang, Z. H. \& Jiang, Q. (2006). Electroless Ni-P deposition plus zinc phosphate coating on AZ91D magnesium alloy. Surface and Coatings Technology, 200, 20-21, 5956-5962, 0257-8972.

Liu, C. S. \& Fang, S. K. (2005). Formation of cerium conversion coatings on AZ31 magnesium alloys. Journal of The Electrochemical Society, 152, 2, B54-B59, 0013-4651.

Liu, H.; Szunerits, S.; Xu, W. \& Boukherroub, R. (2009). Preparation of superhydrophobic coatings on zinc as effective corrosion barriers. ACS Applied Materials E Interfaces, 1 , 6, 1150-1153, 1944-8244.

Liu, K.; Zhang, M.; Zhai, J.; Wang, J. \& Jiang, L. (2008). Bioinspired construction of Mg-Li alloys surfaces with stable superhydrophobicity and improved corrosion resistance. Applied Physics Letters, 92, 18, 183103, 0003-6951.

Liu, T.; Chen, S.; Cheng, S.; Tian, J.; Chang, X. \& Yin, Y. (2007). Corrosion behavior of superhydrophobic surface on copper in seawater. Electrochimica Acta, 52, 28, 8003-8007, 0013-4686.

Liu, Z. \& Gao, W. (2006). Electroless nickel plating on AZ91 Mg alloy substrate. Surface and Coatings Technology, 200, 16-17, 5087-5093, 0257-8972.

Ma, H.; Chen, S.; Niu, L.; Zhao, S.; Li, S. \& Li, D. (2002). Inhibition of copper corrosion by several Schiff bases in aerated halide solutions. Journal of Applied Electrochemistry, 32, 1, 65-72, 0021-891X.

Montemor, M. F. \& Ferreira, M. G. S. (2007). Electrochemical study of modified bis[triethoxysilylpropyl] tetrasulfide silane films applied on the AZ31 Mg alloy. Electrochimica Acta, 52, 27, 7486-7495, 0013-4686.

Mordike, B. L. \& Ebert, T. (2001). Magnesium: Properties - applications - potential Materials. Science and Engineering A, 302, 1, 37-45, 0921-5093.

Nordlien, J. H.; Ono, S.; Masuko, N. \& Nisancioglu, K. (1997). A TEM investigation of naturally formed oxide films on pure magnesium. Corrosion Science, 39, 8, 1397$1414,1757-1761$.

Ogawa, M. \& Asai, S. (2000). Hydrothermal synthesis of layered double hydroxidedeoxycholate intercalation compounds. Chemistry of Materials, 12, 11, 3253-3255, 0897-4756.

Phani, A. R.; Gammel, F. J. \& Hack, T. (2006). Structural, mechanical and corrosion resistance properties of $\mathrm{Al}_{2} \mathrm{O}_{3}-\mathrm{CeO}_{2}$ nanocomposites in silica matrix on $\mathrm{Mg}$ alloys by a sol-gel dip coating technique. Surface and Coatings Technology, 201, 6, 3299-3306, 0257-8972.

Pourbaix, M. (1974). Atlas of Electrochemical Equilibria in Aqueous Solutions, p. 458, National Association of Corrosion Engineers, 65-11670, Huston, Texas, USA.

Qian, B. \& Shen, Z. (2005). Fabrication of superhydrophobic surfaces by dislocation-selective chemical etching on aluminum, copper, and zinc substrates. Langmuir, 21, 20, 9007 9009, 0743-7463.

Qian, M. \& Zeng, H. C. (1997). Synthesis and characterization of Mg-Co catalytic oxide materials for low-temperature $\mathrm{N}_{2} \mathrm{O}$ decomposition. Journal of Materials Chemistry, 7 , 3, 493-499, 0959-9428.

Qu, M.; Zhang, B.; Song, S.; Chen, L.; Zhang, J. \& Cao, X. (2007). Fabrication of superhydrophobic surfaces on engineering materials by a solution-immersion process. Advanced Functional Materials, 17, 4, 593-596, 1616-301X. 
Rives, V. \& Ulibarri, M. A. (1999). Layered double hydroxides (LDH) intercalated with metal coordination compounds and oxometalates. Coordination Chemistry Reviews, 181, 1, 61-120, 0010-8545.

Roach, P.; Shirtchliffe, N. J. \& Newton, M. I. (2008). Progess in superhydrophobic surface development. Soft Matter, 4, 2, 224-240, 1744-683X.

Schultze, J. W. \& Lohrengel, M. M. (2000). Stability, reactivity and breakdown of passive films. Problems of recent and future research. Electrochimica Acta, 45, 15-16, 24992513, 0013-4686.

Shi, F.; Wang, Z. \& Zhang, X. (2005). Combining a layer-by-layer assembling technique with electrochemical deposition of gold aggregates to mimic the legs of water striders. Advanced Materials, 17, 8, 1005-1009, 0935-9648.

Shirtcliffe, N. J.; McHale, G.; Newton, M. I. \& Perry, C. C. (2003). Intrinsically superhydrophobic organosilica sol-gel foams. Langmuir, 19, 14, 5626-5631, 07437463.

Shirtcliffe, N. J.; McHale, G.; Newton, M. I. \& Perry, C. C. (2005). Wetting and wetting transitions on copper-based super-hydrophobic surfaces. Langmuir, 21, 3, 937-943, 0743-7463.

Singh, A.; Steely, L. \& Allcock, H. R. (2005). Poly[bis(2,2,2-trifluoroethoxy)phosphazene] Superhydrophobic Nanofibers. Langmuir, 21, 25, 11604-11607, 0743-7463.

Song, G.; Atrens, A.; Stjohn, D.; Nairn, J, \& Li, Y. (1997). The electrochemical corrosion of pure magnesium in $1 \mathrm{~N} \mathrm{NaCl}$. Corrosion Science, 39, 5, 855-875, 1757-1761.

Song, G. -L. (2010). "Electroless" deposition of a pre-film of electrophoresis coating and its corrosion resistance on a Mg alloy. Electrochimica Acta, 55, 7, 2258-2268, 0013-4686.

Tamar, Y. \& Mandler, D. (2008). Corrosion inhibition of magnesium by combined zirconia silica sol-gel films. Electrochimica Acta, 53, 16, 5118-5127, 0013-4686.

Thieme, M.; Frenzel, R.; Schmidt, S.; Simon, F.; Hennig, A.; Worch, H.; Lunkwitz, K. \& Scharnweber, D. (2001). Generation of ultrahydrophobic properties of aluminium A first step to self-cleaning transparently coated metal surfaces. Advanced Engineering Materials, 3, 9, 691-695, 1438-1656.

Thieme, M. \& Worch, H. (2006). Ultrahydrophobic aluminium surfaces: properties and EIS measurements of different oxidic and thin-film coated states. Journal of Solid State Electrochemistry, 10, 9, 737-745, 1432-8488.

Wang, S.; Feng, L. \& Jiang, L. (2006). One-step solution-immersion process for the fabrication of stable bionic superhydrophobic surfaces. Advanced Materials, 18, 6, 767-770, 0935-9648.

Ha, W. \& Kim, Y. -J. (2006). Effects of cover gases on melt protection of Mg alloys. Journal of Alloys and Compounds, 422, 1-2, 208-213, 0925-8388.

Wu, X.; Ma, H.; Chen, S.; Xu, Z. \& Sui, A. (1999). General equivalent circuits for faradaic electrode processes under electrochemical reaction control. Journal of The Electrochemical Society, 146, 5, 1847-1853, 0013-4651.

Wu, Y.; Sugimura, H.; Inoue, Y. \& Takai, O. (2002). Thin films with nanotextures for transparent and ultra water-repellent coatings produced from trimethylmethoxysilane by microwave plasma CVD. Chemical Vapor Deposition, 8, 2, 47-50, 0948-1907. 
Wu, Y.; Bekke, M.; Inoue, Y.; Sugimura, H.; Kitaguchi, H.; Liu, C. \& Takai, O. (2004). Mechanical durability of ultra-water-repellent thin film by microwave plasmaenhanced CVD. Thin Solid Films, 457, 1, 122-127, 0040-6090.

Xu, W.; Liu, H.; Lu, S.; Xi, J. \& Wang, Y. (2008). Fabrication of superhydrophobic surfaces with hierarchical structure through a solution-immersion process on copper and galvanized iron substrates. Langmuir, 24, 19, 10895-10900, 0743-7463.

$\mathrm{Xu}, \mathrm{Z}$. P. \& Zeng, H. C. (1999). Interconversion of brucite-like and hydrotalcite-like phases in cobalt hydroxide compounds. Chemistry of Materials, 11, 1, 67-74, 0897-4756.

$\mathrm{Xu}, \mathrm{Z}$. P. \& Zeng, H. C. (2000). In-situ generation of maximum trivalent cobalt in synthesis of hydrotalcite-like compounds $\mathrm{Mg}_{x} \mathrm{Co}_{1-x-y} \mathrm{Co}_{\mathrm{y}} \mathrm{II}(\mathrm{OH})_{2}\left(\mathrm{NO}_{3}\right)_{y} n \mathrm{H}_{2} \mathrm{O}$. Chemistry of Materials, 12, 9, 2597-2603, 0897-4756.

$\mathrm{Xu}$, Z. P. \& Zeng, H. C. (2001). Abrupt structural transformation in hydrotalcite-like compounds $\mathrm{Mg}_{1-\mathrm{x}} \mathrm{Al}_{\mathrm{x}}(\mathrm{OH})_{2}\left(\mathrm{NO}_{3}\right)_{\mathrm{x}} n \mathrm{H}_{2} \mathrm{O}$ as a continuous function of nitrate anions. The Journal of Physical Chemistry B, 105, 9, 1743-1749, 1520-6106.

$\mathrm{Xu}, \mathrm{Z}$. P. \& Braterman, P. S. (2003). High affinity of dodecylbenzene sulfonate for layered double hydroxide and resulting morphological changes. Journal of Materials Chemistry, 13, 2, 268-273, 0959-9428.

Yates, K. \& West, R. H. (1983). Monochromatized Ag La X-rays as a source for higher energy XPS, Surface and Interface Analysis, 5, 4, 133-138, 0142-2421.

Yong, Z.; Zhu, J.; Qiu, C. \& Liu, Y. (2008). Molybdate/phosphate composite conversion coating on magnesium alloy surface for corrosion protection. Applied Surface Science, 255, 5, 1672-1680, 0169-4332.

Zhang, X.; Shi, F.; Yu, X.; Liu, H.; Fu, Y.; Wang, Z.; Jiang, L. \& Li, X. (2004). Polyelectrolyte multilayer as matrix for electrochemical deposition of gold clusters: toward superhydrophobic surface. Journal of the American Chemical Society, 126, 10, 3064-3065, 0002-7863.

Zhu, W. Q.; Feng, X. J.; Feng, L. \& Jiang, L. (2006). UV-manipulated wettability between superhydrophobicity and superhydrophilicity on a transparent and conductive $\mathrm{SnO}_{2}$ nanorod film. Chemical Communications, 2006, 26, 2753-2755, 1359-7345. 


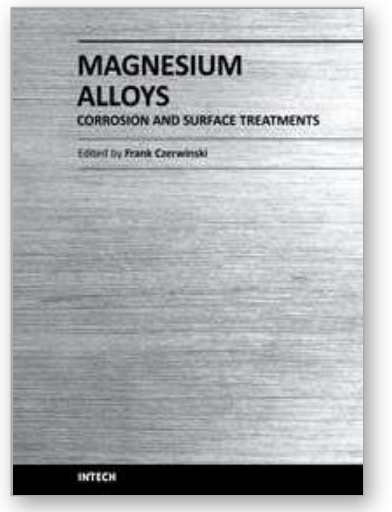

\author{
Magnesium Alloys - Corrosion and Surface Treatments \\ Edited by Frank Czerwinski
}

ISBN 978-953-307-972-1

Hard cover, 344 pages

Publisher InTech

Published online 14, January, 2011

Published in print edition January, 2011

A resistance of magnesium alloys to surface degradation is paramount for their applications in automotive, aerospace, consumer electronics and general-purpose markets. An emphasis of this book is on oxidation, corrosion and surface modifications, designed to enhance the alloy surface stability. It covers a nature of oxides grown at elevated temperatures and oxidation characteristics of selected alloys along with elements of general and electrochemical corrosion. Medical applications are considered that explore bio-compatibility of magnesium alloys. Also techniques of surface modifications, designed to improve not only corrosion resistance but also corrosion fatigue, wear and other behaviors, are described. The book represents a valuable resource for scientists and engineers from academia and industry.

\title{
How to reference
}

In order to correctly reference this scholarly work, feel free to copy and paste the following:

Takahiro Ishizaki, Sunhyung Lee and Katsuya Teshima (2011). High Functionalization of Magnesium Alloy Surface by Superhydrophobic Treatment, Magnesium Alloys - Corrosion and Surface Treatments, Frank Czerwinski (Ed.), ISBN: 978-953-307-972-1, InTech, Available from:

http://www.intechopen.com/books/magnesium-alloys-corrosion-and-surface-treatments/high-functionalizationof-magnesium-alloy-surface-by-superhydrophobic-treatment

\section{INTECH}

open science | open minds

\author{
InTech Europe \\ University Campus STeP Ri \\ Slavka Krautzeka 83/A \\ 51000 Rijeka, Croatia \\ Phone: +385 (51) 770447 \\ Fax: +385 (51) 686166 \\ www.intechopen.com
}

\author{
InTech China \\ Unit 405, Office Block, Hotel Equatorial Shanghai \\ No.65, Yan An Road (West), Shanghai, 200040, China \\ 中国上海市延安西路65号上海国际贵都大饭店办公楼 405 单元 \\ Phone: +86-21-62489820 \\ Fax: +86-21-62489821
}


(C) 2011 The Author(s). Licensee IntechOpen. This chapter is distributed under the terms of the Creative Commons Attribution-NonCommercialShareAlike-3.0 License, which permits use, distribution and reproduction for non-commercial purposes, provided the original is properly cited and derivative works building on this content are distributed under the same license. 